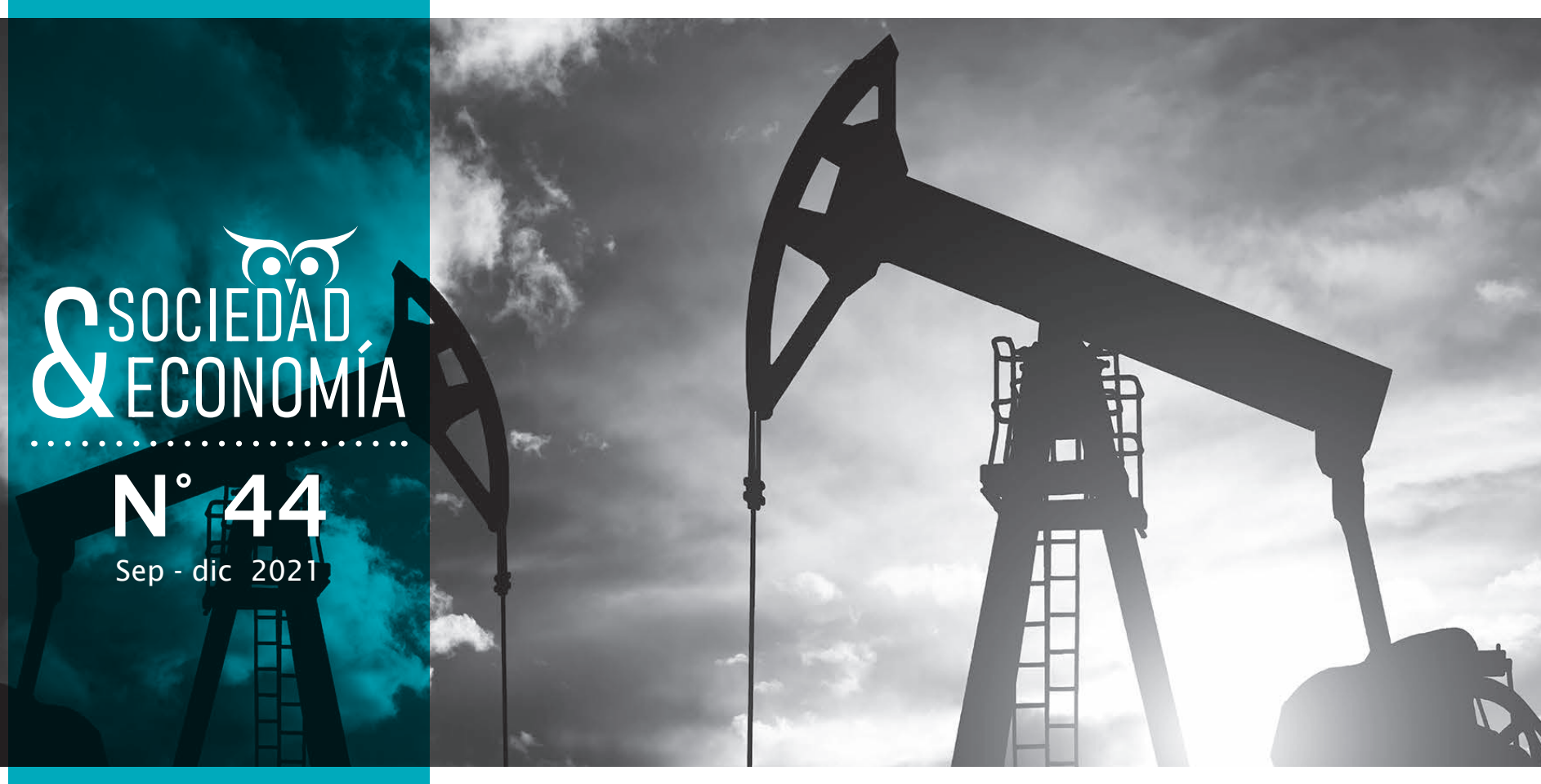

\title{
Políticas de posicionamiento del sector hidrocarburífero argentino tras la estatización parcial de YPF (2012-2015)
}

Positioning policies of the Argentine Hydrocarbons Sector After the Partial Nationalization of YPF (2012-2015)

\section{Diego Pérez-Roig'}

Centro de Estudios e Investigaciones Laborales (CEIL-CONICET), Ciudad Autónoma de Buenos Aires, Argentina 실. dperezroig@gmail.com

(D) https://orcid.org/0000-0002-1605-8034

Recibido: 14-01-2021 Aceptado: 19-07-2021 Publicado: 01-09-2021 


\title{
Resumen
}

Este artículo analiza las políticas diseñadas e implementadas en Argentina, entre 2012 y 2015 , con el propósito de promover la obtención de hidrocarburos de reservorios "no convencionales". En 2012, la Ley "de Soberanía Hidrocarburífera" dispuso la recuperación del control estatal de Yacimientos Petrolíferos Fiscales (YPF) y convirtió a aquellos recursos en objetivos estratégicos de la política energética. Ello implicó la posterior adopción de un amplio abanico de medidas destinadas a atraer inversores extranjeros. Desde la perspectiva de la internacionalización del capital y del Estado, se muestra a ese conjunto como "políticas de posicionamiento" que deben enfrentar distintos límites y contradicciones asociadas a la volatilidad del mercado mundial, la dinámica local de la acumulación y la producción de consenso. A tal fin, se empleó una estrategia metodológica mixta, basada en la triangulación de métodos y técnicas de recolección de información y análisis de datos.

Palabras clave: Estado; Argentina; política energética; hidrocarburos; inversión extranjera.

Clasificación JEL: E6, F0, H0, L3, O2, Q4.

\begin{abstract}
This article analyzes the policies designed and implemented in Argentina, between 2012 and 2015, with the purpose of promoting the obtaining of hydrocarbons from "unconventional" reservoirs. In 2012, the "Hydrocarbon Sovereignty" Law provided for the recovery of state control of Yacimientos Petrolíferos Fiscales (YPF) and turned those resources into strategic objectives of the energy policy. This implied the subsequent adoption of a wide range of measures aimed at attracting foreign investors. From the perspective of the internationalization of capital and the State, this set of measures is shown as "positioning policies" that must face different limits and contradictions associated with the volatility of the world market, the local dynamics of accumulation and the production of consensus. To this end, a mixed methodological strategy was employed, based on the triangulation of methods and techniques of information collection and data analysis.

Keywords: State; Argentina; energy policy; hydrocarbons; foreign investment.

JEL Classification: E6, F0, H0, L3, O2, Q4.

\section{Financiación}

El presente artículo se desprende de una investigación doctoral financiada por el Consejo Nacional de Investigaciones Científicas y Técnicas (CONICET).
\end{abstract}

\section{Conflicto de interés}

El autor declara no tener ningún conflicto de interés en la publicación de este artículo. 
Sociedad y Economía N 44 (Sep - dic 2021) / e-ISSN: 2389-9050 / e10510930

Políticas de posicionamiento del sector hidrocarburífero

argentino tras la estatización parcial de YPF (2012-2015)

\section{Introducción}

La Ley "de Soberanía Hidrocarburífera" (LSH) No $26.741 / 2012$ declaró "de interés público nacional y como objetivo prioritario" el logro del autoabastecimiento de hidrocarburos (Congreso de la Nación Argentina, 2012, Art. 1). En virtud de ese propósito, estableció la utilidad pública y expropiación del $51 \%$ de las acciones Clase D de YPF S.A. pertenecientes a Repsol. La norma fue el desenlace de un agudo conflicto motivado por las consecuencias macroeconómicas del desempeño de la compañía y produjo el cambio más importante en el Estado durante la postconvertibilidad (Pérez-Roig, 2020a).

Entonces, una parte relevante de los desequilibrios externos y fiscales se explicaba por la declinante performance del sector petrolero. Uno de los aspectos reprochados a la anterior conducción de YPF fue la debilidad global de la inversión y, en particular, la destinada a la obtención de hidrocarburos de reservorios "no convencionales" (HNC) (Ministerio de Planificación Federal, Inversión Pública y Servicios, y Ministerio de Economía y Finanzas Públicas, 2012, pp. 76-83). Existían diversos indicios acerca de una vasta dotación nacional de recursos. En los últimos dos años, Repsol YPF había realizado cuatro anuncios acerca del hallazgo y la certificación de reservas en la formación geológica Vaca Muerta². En febrero de 2012, tras obtener los resultados de una auditoría externa, la petrolera había afirmado que "Argentina [tenía] la posibilidad de replicar la revolución que los hidrocarburos no convencionales [habían] significado para Estados Unidos" (Repsol YPF, 2012a, p. 2). Asimismo, en abril de 2011 , la Energy Information Administration (EIA, 2011) había estimado en 774 trillion cubic feet (TCF) el volumen de recursos gasíferos shale técnicamente recuperables, lo cual ubicaba a Argentina en tercer lugar a nivel mundial. Dos años más tarde, el mismo organismo elevó esa evaluación a 802 TCF y también consideró en torno a los 27 mil millones de barriles los recursos técnicamente recuperables de shale oil (EIA, 2013).

2 Roca "madre" de hidrocarburos que se extiende en un área de $30.000 \mathrm{~km}^{2}$ del subsuelo de las provincias de Neuquén, Mendoza, Río Negro y La Pampa.
La ley convirtió a los HNC en objetivos estratégicos de la política petrolera del Estado. El Gobierno presumía que, frente a la inexorable maduración de los yacimientos tradicionales, la obtención de esos recursos no solo posibilitaría el abastecimiento doméstico, sino también la inserción del país en cadenas globales de valor. Consecuentemente, la LSH dio paso a la implementación de un amplio abanico de medidas de promoción de HNC, fundadas en la atracción de inversores internacionales. Pese a la volatilidad del precio mundial del petróleo, entre 2014 y 2015 , esos estímulos se materializaron en un primer ciclo masivo de desarrollo en el área Loma Campana (Neuquén), operada por YPF en asociación con Chevron.

El objetivo del presente artículo es analizar las políticas de promoción implementadas entre 2012 y 2015 , desde la perspectiva de la internacionalización del capital y del Estado (Holloway, 1993; Hirsch, 1999; Jessop, 2008; von-Braunmühl, 2017). Este enfoque, inexplorado por la literatura existente sobre la temática (Bravo, 2015; Giuliani, 2017; Bilmes, 2018; entre otros), o solo parcialmente empleado para el análisis del contrato entre YPF y Chevron (García-Zanotti, 2017), contribuye a la comprensión de la unidad de esas políticas de desarrollo en tanto "políticas de posicionamiento" (Hirsch, 1999), así como también a la interpretación de sus alcances, límites y contradicciones. El recorte temporal del estudio se extiende desde el momento inmediatamente posterior a la sanción de la LSH, hasta la finalización del gobierno del PJ-Frente para la Victoria. Las políticas adoptadas por la administración de la Alianza Cambiemos (diciembre 2015-diciembre 2019) implican rupturas que se entrelazan con una agudización de las contradicciones de la postconvertibilidad (Piva, 2020a), y podrán ser analizadas a la luz de los resultados de este trabajo.

El próximo apartado presenta los presupuestos teóricos e históricos del análisis. Por un lado, reponemos las conclusiones de dos trabajos recientes acerca de la política hidrocarburífera en el período 2002-2011 y la recuperación del control de YPF (Pérez-Roig, 2020a; 2021). Por el otro, incorporamos herramien- 
tas intelectuales que consideramos productivas para el análisis de las políticas posteriores. Esquemáticamente, la argumentación articula tres proposiciones: a) el abastecimiento de energía forma parte de un complejo empírico de prerrequisitos de la acumulación sobre el cual el Estado interviene privilegiadamente; b) tal intervención enfrenta desafíos concretos planteados por la internacionalización de los capitales, las cambiantes características técnicas de la producción y los límites del modo de acumulación; c) la política estatal debe absorber la presión ejercida por estos factores, pero ello puede socavar las bases de su consenso a nivel interno.

El siguiente apartado analiza las políticas implementadas en el período 2012-2015, tras la aprobación y reglamentación de la LSH. Varias de ellas podrían ser objeto de un abordaje in extenso, pero lo que nos interesa aquí es observar de qué forma buscaron posicionar a la geología nacional en la arena de competencia mundial y qué contradicciones abrieron para la legitimación del Estado. Esta parte del trabajo se basa en la construcción y el análisis cualitativo del corpus jurídico orientado a la promoción de HNC. Para ello recurrimos al sitio de Información Legislativa y Documental (InfoLEG) del Ministerio de Justicia y Derechos Humanos de la Nación. También nos apoyamos en información pública suministrada por capitales del sector y apelamos a archivos periodísticos para el registro documental de la "cuestión". Por su parte, la observación de los resultados de las políticas es predominantemente cuantitativa y se basa en el análisis estadístico de datos suministrados por Secretaría de Energía de la Nación (2020) y el Instituto Nacional de Estadística y Censos (INDEC, 2020).

Finalmente, las conclusiones sintetizan los contenidos más importantes del artículo y presentan la hipótesis de trabajo a considerar en futuras indagaciones.

\section{Internacionalización y "soberanía hidrocarburífera"}

La acción estatal se desenvuelve como parte de un campo dinámico que la impregna de parcia- lidad, inconsistencia e incertidumbre (Oszlak y O’Donnell, 1995; Álvarez-Huwiler y Bonnet, 2018 ). Sobre esta base general, la política hidrocarburífera puede ser caracterizada como un tipo específico de intervención orientado a garantizar condiciones generales para la acumulación de capital. Las grandes tendencias del modo de producción capitalista se desarrollan al nivel del capital entendido como totalidad social (Marx, 2009), unidad que emerge a espaldas de los sujetos a través de sus múltiples interacciones en el mercado (Rubin, 1974). Pero la conformación de tal unidad no puede ser atribuida únicamente a la competencia, pues la producción de carácter privado, a su vez, obtura el desenvolvimiento de relaciones que configuran el entorno social necesario para la propia existencia del capital.

Como aparato sustraído a la producción de plusvalor, el Estado es una institución capaz de suplir "dentro de la indisputada armazón del capital las necesidades inmanentes que el capital ignora" (Altvater, 1977, p. 92). Frente a esas necesidades, podemos referirnos teóricamente al Estado como un "capitalista colectivo" (Negri, 2003), que no suprime ni tampoco es instrumentalizado por los intereses individuales en conflicto. Libre de la constricción inmediata de la competencia, el Estado cumple una serie de funciones sociales generales, entre las que se encuentra la "política infraestructural", esto es, la generación de prerrequisitos materiales de la producción que no son redituables (Altvater, 1977).

Ahora bien, tal cumplimiento se desarrolla concretamente a través de una doble determinación, que supone una relación contradictoria con la reproducción capitalista (Hirsch, 1978). Como forma particularizada -no específicamente económica- del dominio de clase, el Estado se eleva por encima del proceso inmediato de producción de plusvalor, recibiendo un influjo directo del conflicto y el cambio en la constelación de fuerza entre clases y grupos sociales. Al mismo tiempo, sin embargo, esa "autonomía" del momento político se encuentra constreñida por una relación objetiva con la acumulación de capital, fundamento material del poder estatal. Surge así una contradicción inherente a la acción del Estado, que es la que, 
en última instancia, impregna de contingencia y parcialidad a su intervención.

La creación de infraestructura o prerrequisitos de la producción como el abastecimiento energético es parte de un complejo empírico de funciones del Estado que puede considerarse "objetivamente necesario", aunque solo en su carácter y estructura general, y no en su forma concreta de cumplimiento (Hirsch, 1978). Las condiciones que serán objeto de provisión, la modalidad de intervención y su resultado son un producto histórico. Entre otros factores, ello dependerá de la penetración y las mutaciones en la forma del capital, de la mundialización de la producción y el intercambio, así como del grado de desarrollo de las fuerzas productivas.

En el caso del sector petrolero, la internacionalización del capital es un hecho de larga data (Yergin, 2008). Pero ahora adquiere significado como expresión de un fenómeno general que afecta el diseño y la implementación de la política estatal. La movilidad y la tendencia a la formación del mercado mundial se encuentran inscritas en el propio concepto de capital (Holloway, 1994). En sus primeras etapas, esta propensión se manifestó como una progresiva subsunción formal de amplias regiones del planeta, a través de la coerción ejercida por el dinero y la expansión del tráfico de mercancías. Desde mediados de los setenta, en cambio, se verifica una acelerada mundialización del modo específicamente capitalista de extracción de excedentes (Astarita, 2004), fundada en la internacionalización del capital productivo (Piva, 2020b).

Esta fase de la internacionalización se desarrolló, primero, como respuesta ciega -una "fuga" temporal y espacial (Holloway, 2003; Harvey, 2007)- frente al deterioro de las condiciones de valorización en los capitalismos avanzados. Luego, como estrategia ofensiva de clase estatalmente coordinada a través del set de políticas neoliberales (Bonnet, 2007). El reforzamiento mutuo de procesos de desregulación a escala nacional e internacional abrió relaciones sociales y ámbitos inéditos a la valorización (Harvey, 2008). A largo plazo, la flexibilidad global de los mercados de dinero, mercancías e inversiones productivas dio nueva forma a la relación entre Estado y capital (Holloway, 1993; von-Braunmühl, 2017), sometiendo cada vez más directamente a la política a las estrategias internacionales de competencia.

El proceso de acumulación sigue desenvolviéndose como unidad contradictoria que no existe globalmente sino a través de una pluralidad de Estados y espacios nacionales de valor (Astarita, 2010). Y el Estado nacional continúa siendo la escala de regulación por excelencia de las relaciones capitalistas. Es decir, de aseguramiento de la cohesión de una sociedad dividida en clases y atravesada por otras escisiones y conflictos, con base en la formación de determinados "intereses nacionales" y coaliciones transclasistas asociadas a ellos (Poulantzas, 2007; Jessop, 2008). Pero se han modificado los determinantes internacionales del intervencionismo estatal. El movimiento global del capital, operado bajo el poder coordinador del dinero (Harvey, 2008), coloca a la política nacional frente a "la creciente presión de optimar su 'posicionamiento' en la competencia internacional respecto a las condiciones de valorización" (Hirsch, 1999, p. 77).

Distintos autores dan cuenta del cambio en la forma de Estado a partir de la noción de "Estado nacional de competencia" o "competitivo" (Hirsch, 1999; Jessop, 2008). Genéricamente, se trata de un Estado que busca garantizar el crecimiento económico y asegurar ventajas competitivas para los capitales que se establecen dentro de sus fronteras, a partir de la producción de condiciones económicas y políticas necesarias para triunfar en la competencia con actores y espacios económicos localizados en otros Estados (Jessop, 2008). Esta forma tiende a dislocar el cumplimiento de "funciones" de acumulación y producción de consenso (O'Connor, 1974). La creciente subordinación del conjunto de las áreas de intervención estatal a la política económica de posicionamiento (Jessop, 2008), colisiona con el proceso político democrático de formación de una voluntad soberana (Hirsch, 1999). Mientras que la legitimación de la dominación política continúa asumiendo una forma estatal-territorial, la re- 
lación objetiva del Estado con la acumulación aparece como presión exterior. Aquella doble determinación de la forma-estado se presenta, entonces, como contradicción entre Estado nacional y capital transnacionalizado, u oposición entre "lo nacional" y "lo global" (Piva, 2020b).

\subsection{LSH y recuperación del control de $\mathrm{YPF}^{3}$}

La LSH se inscribe dentro de un conjunto de políticas implementadas por el Estado durante la postconvertibilidad con el fin de promover inversiones que potenciaran el desarrollo del sector. Hasta 2011, esas intervenciones, en gran medida fallidas, habían comprendido una amplia diversidad de instrumentos: la creación de Energía Argentina S.A. (ENARSA) y el respaldo a una "argentinización" de YPF mediante el ingreso de un grupo económico local a su composición accionaria; la implementación de planes de estímulo y de apertura de nuevas áreas a la valorización; la consolidación del dominio provincial de los recursos del subsuelo, aspecto del régimen jurídico legado por las reformas neoliberales; entre otros.

En tal marco, puede afirmarse que la LSH receptó el influjo de tres factores. En primer lugar, la constitución del sector petrolero argentino como un escenario más de la competencia internacional, legado estructural de las reformas neoliberales (Pérez-Roig, 2020a; 2020b). Aunque los capitales que operaban en el país obtenían importantes beneficios (Barrera, 2013), aquello suponía una creciente subordinación de las inversiones a sus estrategias globales. De modo que el desarrollo de la industria no dependía de la rentabilidad absoluta obtenida en el espacio nacional de valor, sino de su competitividad frente a otras oportunidades de negocio existentes a nivel mundial.

En segundo lugar, ese desarrollo se encontraba condicionado, desde el punto de vista geológico, por la necesidad de asimilar objetivos

3 Como adelantábamos, este apartado recupera las conclusiones de dos trabajos previos (Pérez-Roig, 2020a; 2021). más complejos que los tradicionales (Cruz, 2005). La incorporación de nuevos paradigmas y tecnologías de explotación demandaba un notable incremento de la inversión. Pero tal potenciamiento resultaba desincentivado por la implementación de distintas políticas de separación del espacio nacional respecto de la dinámica de precios en el mercado mundial (Pérez-Roig, 2021). Si, por un lado, las retenciones a las exportaciones y los controles internos de precios eran relevantes para el sostenimiento del esquema macroeconómico de la postconvertibilidad, por el otro, implicaban límites a la movilidad y las posibilidades de realización de ganancias de los capitales.

En tercer lugar, la reticencia inversora se tradujo en sostenidas caídas de la producción y las reservas comprobadas. En un contexto de crecimiento económico sostenido y de reverdecimiento de ramas mercado-internistas del aparato industrial, la creciente brecha entre oferta y demanda interna de hidrocarburos solo pudo resolverse mediante la importación de combustibles (Barrera y Serrani, 2018). Hacia 2011, el déficit de la balanza comercial energética se sobreimprimió a una pérdida general de vitalidad del desempeño macroeconómico, cuyo fundamento fue el carácter predominantemente capital-extensivo de la acumulación (Piva, 2018). La imposibilidad de trascender las debilidades del modo de acumulación en lo que respecta a la producción de bienes de capital y tecnología (Gaggero et al., 2014), subordinó a la postconvertibilidad a un frágil compromiso de condiciones internas y externas, cuyo fundamento último era la existencia de términos de intercambio favorables para los productos de exportación. El progresivo deterioro de ambos frentes se expresó más visiblemente en la reaparición del estrangulamiento externo de la economía y la pérdida del superávit fiscal. En un marco de dificultades para obtener financiamiento a tasas "razonables", esos resultados negativos ejercían creciente presión sobre las reservas del Banco Central y la administración del tipo de cambio, abriendo la posibilidad de una crisis de balanza de pagos.

La LSH puede ser entendida como intervención del Estado orientada a asegurar condiciones 
generales para la producción. La declinante performance del sector no sólo afectaba la provisión de energía necesaria para la reproducción material de la postconvertibilidad. También desintegraba la "autonomía estatal" para el arbitraje del conflicto posibilitada por los superávits fiscal y de cuenta corriente, al forzar un mayor empleo de recursos para adquirir y subsidiar el consumo de combustibles.

Sin embargo, la forma que adoptó la persecución de ese objetivo fue el terreno de constitución de una paradoja. La búsqueda del autoabastecimiento expresaba la centralidad de los hidrocarburos como objetos de uso "estratégicos" que debían subsidiar material y económicamente la reproducción de la acumulación en el espacio nacional ${ }^{4}$. Pero ese propósito no subordinó políticamente el desarrollo del sector como ocurría con anterioridad a las reformas neoliberales. Asimismo, el articulado de la ley establecía como fin la obtención de saldos exportables, criterio mercantil de apropiación de los recursos que respondía a la fragilidad externa de la economía. En condiciones de avanzada maduración de los yacimientos tradicionales, la explotación masiva de HNC quedó en el centro de la política hidrocarburífera porque era la única posibilidad de sutura de ambos propósitos.

Este hecho reforzó el entrelazamiento de la lógica política de la intervención estatal con la lógica económica del valor. La movilización masiva de esos recursos demanda -según la letra de la ley- una "maximización de las inversiones", así como la "incorporación de nuevas tecnologías y modalidades de gestión" (Congreso de la Nación Argentina, 2012, Art. 3). La falta de medios materiales y los déficits de capacidades técnicas y organizacionales del Estado empujan, entonces, a la formación de "alianzas estratégicas" con capitales que no pueden ser atraídos sino mediante la asimilación de las presiones que ejerce la competencia internacional. En lo inmediato, ello se expresó en los límites de la estatización de YPF, dados

4 Esta arista de la intervención fue reforzada por el Decreto reglamentario № 1.277/12 (Poder Ejecutivo Nacional, 2012). por el sostenimiento de su condición de sociedad anónima tras la expropiación del 51\% del paquete accionario -lo cual implicaba que, entre sus objetivos, se mantuviera la necesidad de generar valor-. Y, en adelante, supondría una paradoja, pues la apropiación material y simbólica de los hidrocarburos en clave "estratégica" solo podría desarrollarse a través de su producción en cuanto que commodities.

\section{3. "Políticas de posicionamiento" del sector hidrocarburífero}

A continuación, mostraremos que las "políticas de posicionamiento" derivadas de los objetivos de la LSH comprendieron una amplia diversidad de áreas y herramientas de intervención.

\subsection{La nueva orientación de YPF y el acuerdo con Chevron}

La primera señal enviada a los inversores internacionales partió de la conformación de la nueva conducción de YPF. En virtud del artículo $14^{\circ}$ de la $\mathrm{LSH}$, en mayo, el ingeniero Miguel Galuccio fue designado gerente general de la compañía. De perfil técnico, Galuccio representaba un contrapeso a la conducción política global del área energética, a cargo de la Secretaría de Política Económica y Planificación del Desarrollo encabezada por Axel Kicillof. Solo cinco de los diecisiete miembros del nuevo directorio se apartaban de ese perfil: Eduardo Basualdo y Héctor Valle -directores independientes propuestos por el Estado-, Rodrigo Cuesta, Guillermo Pereyra -Secretario General del Sindicato de Petróleo y Gas Privado de Río Negro, Neuquén y La Pampa, designado por el PEN en representación de los trabajadores-y el propio Kicillof.

En agosto, Galuccio dio a conocer la "Estrategia de gestión 2013-2017". El plan partía de tres premisas: la existencia de un sólido portafolio con alto potencial; un drástico giro a partir del cual alrededor del $80 \%$ del cash flow operativo pasaría a ser reinvertido en la producción; y la evolución hacia un escenario en el que los precios locales tenderían a acortar la brecha con 
los de importación. Durante ese quinquenio, el desembolso bruto alcanzaría US\$ 37.200 millones, de los cuales un $73 \%$ se destinaría a explotación y un $4 \%$ a exploración. A mediano plazo, la estrategia proponía la explotación en modo factoría de HNC. Esta sería la base para un posterior desarrollo masivo de Vaca Muerta que posicionara a Argentina como exportador neto de energía.

Para explotar ese potencial, YPF debía articular sus fortalezas -personal calificado, información sobre los reservorios, relaciones gubernamentales-con el aporte de socios que contaran con mayor experticia en formaciones no convencionales y que proveyeran tanto servicios y tecnologías específicas, como el financiamiento necesario para apalancar el plan de inversiones. En este sentido, era un objetivo relevante la captación de un "socio shale" que participara del primer cluster, mediante el ofrecimiento de una tasa interna de retorno atractiva.

La normalización de las relaciones de YPF con el resto de los actores del mercado fue una preocupación de primer orden. Durante las semanas previas a la asunción de Galuccio, el Gobierno formalizó reuniones con ExxonMobil, Chevron, Apache, ConocoPhillips, Total Austral y SINOPEC (YPF, 2012a; 2012b). En estos encuentros, los potenciales socios coincidían en el planteo de cuatro condiciones: progresivo alineamiento de los precios locales con los internacionales; garantía del acuerdo en activos argentinos, como la producción que se obtuviera en Vaca Muerta; plena libertad de exportación de los hidrocarburos extraídos; y eliminación de restricciones para la remisión de utilidades (Olivera, 2012).

Entre diciembre de 2012 y julio de 2013, se alcanzó un "Acuerdo de Proyecto de Inversión" con Chevron (YPF, 2013). La petrolera se comprometió a desembolsar US\$1.240 millones -sobre un total de US\$1.500 millonesen dos etapas, para una primera fase piloto de trabajo sobre $20 \mathrm{~km}^{2}$ de los $395 \mathrm{~km}^{2}$ que estarían afectados entre las áreas Loma La Lata Norte y Loma Campana. Una vez finalizado el proyecto, ambas empresas preveían continuar con el desarrollo del área compartiendo las in- versiones en partes iguales. En la proyección a 35 años, se estimaba que la inversión alcanzaría US\$ 16.000 millones; que se realizarían 1.500 pozos; y que se lograría un plateau de producción de $50.000 \mathrm{bbl}$ y $3 \mathrm{MMm}^{3} / \mathrm{d}$ de gas (YPF, 2013).

Poco tiempo después, se alcanzó un acuerdo de inversión con Dow Argentina, aunque de mucha menor envergadura. En este caso, se buscaría el desarrollo de un proyecto piloto para la explotación de shale gas en el bloque El Orejano. El contrato comprometía una inversión de US\$188 millones, de los cuales US\$ 120 millones serían aportados por Dow. YPF continuaría como operadora de la concesión y, en esta etapa, se realizarían 16 pozos. En la fase de desarrollo masivo, se estimaba que el área podría aportar una producción de $3 \mathrm{MM}$ $\mathrm{m}^{3} / \mathrm{d}$ de gas.

\subsection{El Decreto No 929/13 y la oposición al acuerdo}

Mientras negociaba los términos del contrato con YPF, Chevron enfrentaba graves denuncias y condenas por contaminación en la zona de Lago Agrio, ubicada en la Amazonía ecuatoriana. Según la "Asamblea de Afectados por Texaco" -empresa con la que se había fusionado en 2001-, la contaminación se habría cobrado cientos de vidas humanas, incluyendo la extinción de dos pueblos indígenas y el éxodo obligado de otros cuatro, al tiempo que habría generado cuantiosos perjuicios económicos a comunidades campesinas (Unión de Afectados y Afectadas por las Operaciones Petroleras de Texaco, 2018). En noviembre de 2012, a instancias de un fallo de la justicia de ese país, el Juzgado Nacional Civil de primera instancia № 61 aplicó un embargo sobre las acciones, los dividendos y el $40 \%$ de los depósitos bancarios e ingresos que Chevron obtuviera a futuro por sus operaciones en Argentina. El caso pasó a ser un tema de preocupación -y necesaria intervención- para el Gobierno nacional.

En mayo, la procuradora general de la Nación, Alejandra Gils Carbó, solicitó a la Corte Suprema de Justicia (CSJN) que declarara formalmente admisible un recurso extraordinario de queja 
presentado por Chevron y suspendiera el embargo. Uno de los argumentos del escrito era de indudable índole política. La medida sobre "sujetos que desarrollan una actividad de notorio interés público [...] puede producir perjuicios irreparables a los intereses de la comunidad vinculados con la política energética y el desarrollo económico de nuestro país" (Ministerio Público Fiscal, 2013, p. 10). Finalmente, el 4 de junio, la CSJN hizo lugar a la queja, robusteciendo la fundamentación jurídica de la Procuradora.

La decisión removió una inesperada traba a los planes de estímulo del oficialismo. Por un lado, el acuerdo era una necesaria señal de "confianza por parte de una gran empresa internacional" -como sostuvo Galuccio cuando, junto al CEO de Chevron, fue recibido en la Casa de Gobierno por Cristina Fernández de Kirchner (Casa Rosada, 2013, párr. 10)-. Por el otro, también aparecía como plataforma desde la cual promover la llegada de nuevas inversiones. En efecto, los borradores del contrato prefiguraron los instrumentos normativos que le darían marco.

El 15 de julio, día anterior a que YPF informara el acuerdo, el Gobierno nacional publicó el Decreto No 929/13 (Poder Ejecutivo Nacional, 2013a), de creación del "Régimen de Promoción de Inversión para la Explotación de Hidrocarburos". Como requisito, el régimen exigía la presentación de un proyecto de inversión que implicara la realización de un desembolso directo no inferior a los US\$1.000 millones, a ser ejecutado durante sus primeros cinco años. Como contrapartida, a partir del quinto año de ejecución, los beneficiarios gozarían del derecho a exportar libremente hasta el $20 \%$ de la producción de hidrocarburos líquidos y gaseosos, con una alícuota del $0 \%$ de retenciones. En tal caso, tendrían la libre disponibilidad de las divisas, no estando obligados a ingresarlas a la plaza financiera argentina.

Además del estímulo económico, el decretó avanzó en la definición jurídica de la "Explotación No Convencional de Hidrocarburos", como la extracción "mediante técnicas de estimulación no convencionales" aplicadas en ya- cimientos "de rocas esquisto o pizarra", "areniscas compactas", "capas de carbón" u otras "rocas de baja permeabilidad". Los beneficiarios del régimen podrían solicitar la creación de una "Concesión de Explotación No Convencional de Hidrocarburos" dentro de una ya existente (Poder Ejecutivo Nacional, 2013a). El plazo de esta nueva concesión sería de 25 años, al cual se le podría adicionar en forma anticipada una extensión de 10 años.

El acuerdo reavivó el debate político abierto con motivo de la estatización de YPF. Mientras el Gobierno celebraba y defendía el entendimiento (La Nación, 2013), las críticas hicieron foco sobre diversos temas. Grupos opositores ubicados a su izquierda, pero también sectores afines, interpretaron el contrato como un acto de sumisión "semicolonial" o propicio para una "reprivatización" de YPF (por ejemplo, Pérez-Esquivel, 2013). Ello debido a que implicaba una asociación con capitales de origen estadounidense en el marco de la "Iniciativa Global de Gas de Esquisto" auspiciada por el Departamento de Estado. Asimismo, se denunciaba que la explotación mediante la técnica del fracking derivaría en las mismas prácticas de "saqueo" y destrucción ambiental por las que Chevron había sido recientemente condenada. Ambas presunciones eran alimentadas, a su vez, por la confidencialidad de las cláusulas del contrato (García-Zanotti, 2017; Giustiniani, 2017).

Aunque algunas de estas críticas carecían de sustento, no es menos cierto que, empujado por la necesidad de atraer inversiones, el Gobierno debió adoptar decisiones de considerable costo político. El acuerdo con Chevron generó roces diplomáticos con Ecuador, aliado regional que asumía el conflicto por la Amazonía como una cuestión de Estado. A nivel local, se produjeron importantes episodios de movilización. En Neuquén, la asociación dio origen a una amplia coalición anti-fracking de la que participan organizaciones sindicales, estudiantiles y del pueblo mapuche, asambleas ciudadanas, así como partidos políticos opositores a los oficialismos de la Nación y la Provincia (Riffo, 2017; Hadad et al., 2020; Pérez-Roig y Riffo, 2021). Este espacio multisectorial pro- 
tagonizó diversas acciones de protesta, que alcanzaron su cénit durante la ratificación del contrato de explotación por la Legislatura provincial. La sesión tuvo lugar en medio de un fuerte operativo de seguridad y de una feroz represión, desatada tras la movilización de miles de personas frente al edificio del cuerpo legislativo. Al día siguiente, una manifestación aun más concurrida repudió los hechos.

En Neuquén, la impugnación del acuerdo y el debate público abierto sobre el fracking pusieron en entredicho a la industria petrolera como fuente de bienestar y desarrollo. El surgimiento de este potencial límite político forzó a los gobiernos de la Provincia y de la Nación a redoblar los esfuerzos promocionales de los HNC. Ello tuvo lugar tanto a través de una agresiva estrategia comunicacional, que incluyó una incesante campaña de estigmatización y criminalización del -así denominado- "terrorismo ambiental", como mediante la intervención concreta en las comunidades más próximas a las explotaciones basada en la inversión en infraestructura y servicios (Gutiérrez y Millaman, 2016; Riffo, 2017; Pérez-Roig y Riffo, 2021).

\subsection{El acuerdo indemnizatorio con Repsol}

Pese a su relevancia, la asociación con Chevron no subsanaba la mala reputación del Gobierno entre los inversores internacionales. La completa normalización de las relaciones también exigía una salida negociada al conflicto con Repsol. A comienzos de diciembre de 2012, la compañía elevó la solicitud de inicio de arbitraje ante el CIADI, aunque "sin perjuicio de la posibilidad de las partes de poner fin al procedimiento en cualquier momento en caso de alcanzarse un acuerdo entre ellas" (Repsol YPF, 2012b, párr. 2). En apenas dos semanas, el organismo admitió la demanda y consolidó a Argentina como el país en el mundo con más denuncias.

Durante 2013 , se desarrolló un canal de negociación paralelo. A fines de noviembre, se logró un principio de acuerdo, que fue formalizado en febrero de 2014. Repsol y la República Argentina firmaron un "Convenio de Solución
Amigable y Avenimiento de Expropiación" por el $51 \%$ de YPF S.A. e YPF Gas S.A. Allí se estipulaba que el Gobierno entregaría a Repsol títulos de deuda pública en dólares, compuestos por un paquete fijo de un valor nominal de US\$ 5.000 millones y un paquete complementario, por un importe máximo de US\$ 1.000 millones, que se ajustaría de manera que el valor de mercado de todos los bonos entregados ascendiera, al menos, a US\$ 4.670 millones, con un máximo de US\$ 6.000 millones de valor nominal.

Ratificado el acuerdo por la Junta General de Accionistas de la empresa y por el Congreso de la Nación Argentina (2014a), se entregaron a Repsol títulos de la deuda pública por un importe nominal total de US\$ 5.317 millones, que alcanzaban el valor de mercado promedio de US\$ 4.670 millones previsto. Un día antes, la petrolera española había vendido el 11,86\% de la participación accionaria de YPF que todavía mantenía, por un monto de US\$ 1.255 millones.

\subsection{Estímulos y política de precios}

Si bien los precios del petróleo crudo en el mercado interno ya habían sufrido sucesivas actualizaciones, a partir de 2012 tendió a reducirse cada vez más la brecha con la cotización internacional. La Figura 1 muestra que, entre 2012 y mediados de 2014, la diferencia entre el crudo Medanito de la Cuenca Neuquina y el barril de Brent se ubicó en torno al 38\%, cuando en años anteriores había sido marcadamente superior.

Luego de la suspensión del Programa Petróleo Plus, esta convergencia generó una importante disparidad entre los ingresos netos de las empresas cuya producción se comercializaba en el mercado local y los de aquellas que colocaban su producción en el exterior -pues debían descontar derechos de exportación-. Para garantizar la obtención de niveles similares de rentabilidad, la Resolución No 438/12 (Secretaría de Energía de la Nación, 2012) dispuso que las empresas cuya producción media diaria de petróleo crudo durante 2011 hubiese sido superior a los $1.300 \mathrm{~m}^{3} / \mathrm{d}$, 
Figura 1. Cotizaciones y brecha entre crudo Medanito y Brent (2006-2015)

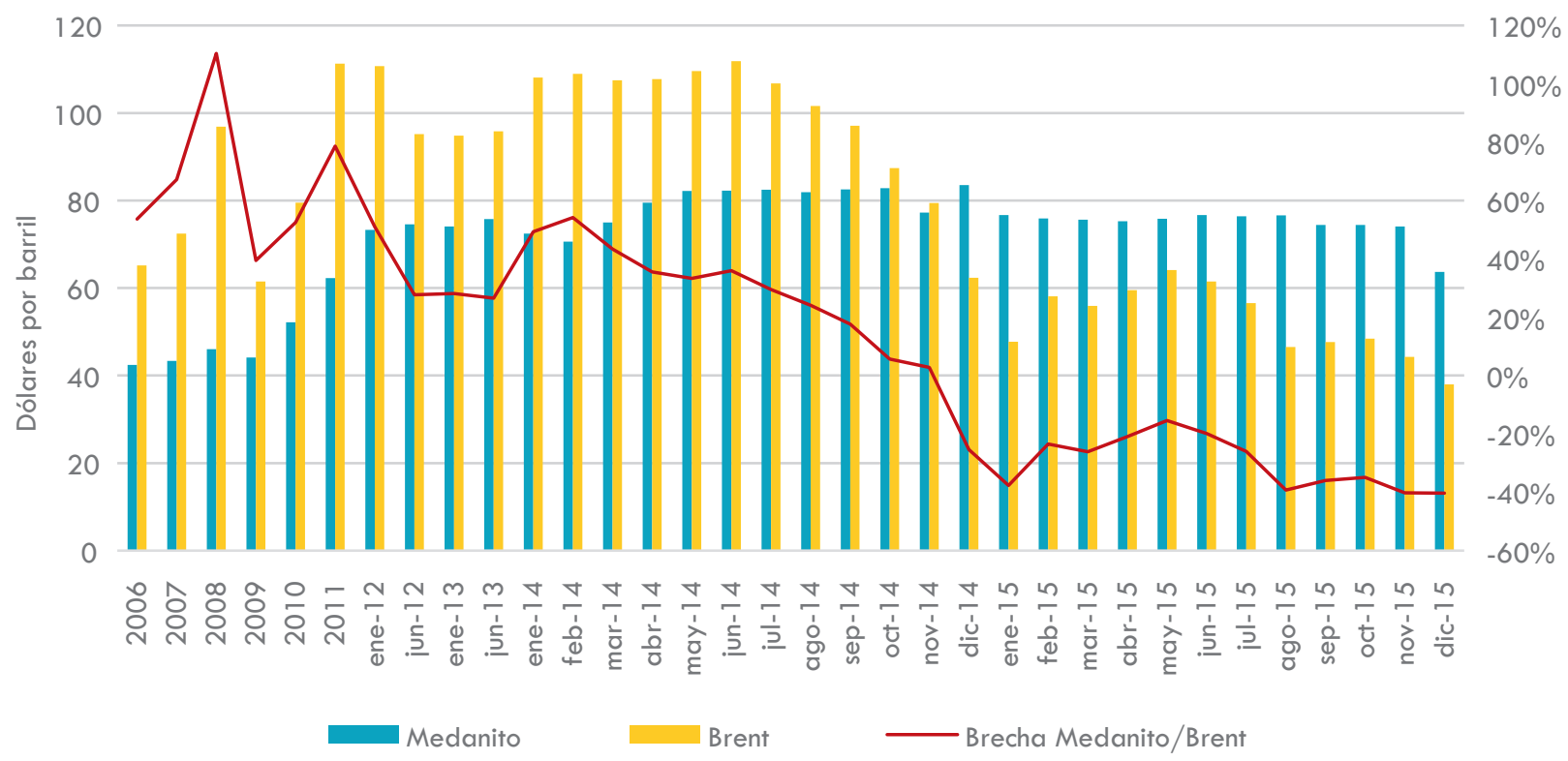

Fuente: elaboración propia basada en datos de Secretaría de Energía de la Nación (2020) y Energy Information Administration (ElA, 2020).

obtendrían una compensación equivalente a US\$ 28 por cada barril exportado, retroactiva a febrero de ese año. Seis meses más tarde, la Resolución No 1/13 (Ministerio de Economía y Finanzas Públicas, 2013) modificó el esquema de derechos de exportación siguiendo el mismo propósito. Se actualizaron los valores de corte y de referencia del barril exportado -de US\$ 42 a US\$ 70 y de US\$ 60,9 a US\$ 80-, lo cual impactó negativamente en la percepción de retenciones (como mostraremos más abajo).

Naturalmente, la convergencia de las cotizaciones se vio reflejada en los surtidores. Devaluación mediante, entre junio de 2012 y junio de 2014, se produjo un shock en el precio de comercialización al público del conjunto de los derivados de hidrocarburos. Como muestra la Figura 2, en la Ciudad Autónoma de Buenos Aires, los incrementos promediaron un $88,6 \%$. En el mismo período, necesitada de caja propia para apalancar su plan de negocios, YPF aumentó sus productos por encima de ese número, con un promedio del 93,5\%.

En el caso del gas, en 2013 se adoptaron dos importantes medidas de promoción. En enero, la Resolución No 1/13 -Comisión de Planificación y Coordinación Estratégica del Plan Nacional de Inversiones Hidrocarburíferas (CPCE, 2013a)creó el "Programa de Estímulo a la Inyección Excedente de Gas Natural" ("Plan Gas I"). Las empresas que obtuvieran la aprobación de sus proyectos recibirían US\$ 7,5/MMBTU por el gas inyectado al mercado interno por encima de su producción base. Pese a las fuertes penalidades dispuestas en caso de incumplimientos, nueve compañías -que explicaban el $80 \%$ de la inyección- adhirieron al programa: YPF, PAE, Total Austral, Wintershall, Sinopec, Enap, Pampa Energía, Roch y Petroquímica Comodoro Rivadavia. En julio, ante la necesidad de ponerlo en operación, y luego de un primer semestre de caída de la producción, la Resolución No 8/13 (CPCE, 2013b) habilitó el pago de compensaciones a cuenta de hasta un $75 \%$ para aquellos proyectos que, aprobados, todavía no habían atravesado por completo el procedimiento administrativo de control técnico y financiero dispuesto reglamentariamente.

En noviembre, la Resolución N 60/13 (CPCE, 2013c) creó el "Programa de Estímulo a la Inyección de Gas Natural para Empresas con Inyección Reducida" ("Plan Gas II"). En este caso, se buscó fomentar la actividad de unidades 
Figura 2. Precio promedio de comercialización de derivados del petróleo en CABA (201 1-2015)

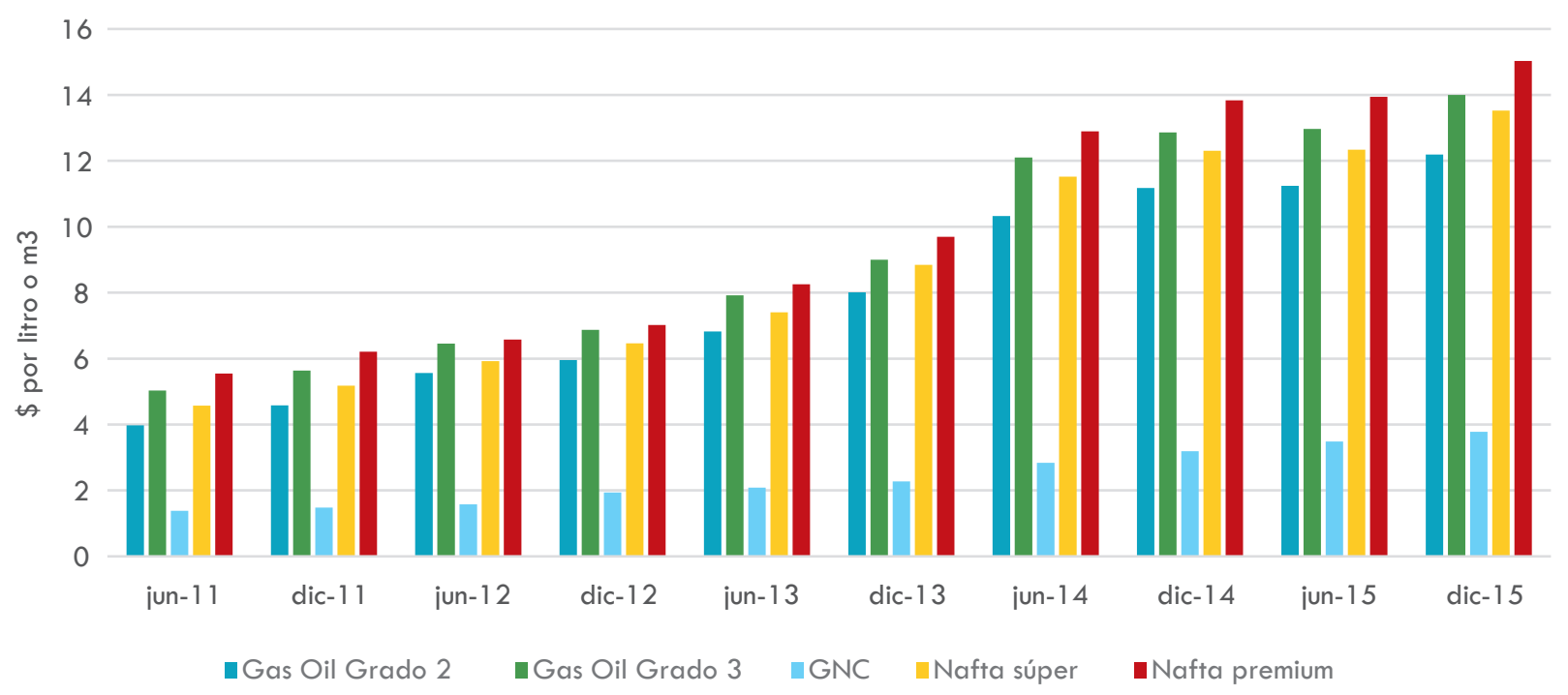

Fuente: elaboración propia basada en datos de Secretaría de Energía de la Nación (2020).

que, por motivos de escala o geológicos, no hubiesen solicitado su incorporación al Plan Gas I. Las empresas recibirían compensaciones trimestrales por parte del Estado nacional, que se determinarían de acuerdo a la relación entre la inyección total, la inyección base y las diferentes curvas teóricas de ajuste -con lo cual, el precio de la inyección excedente podía variar de los US\$ 7,5/MMBTU a los US\$ 4/MMBTU-. Eventualmente, las que hubiesen sido admitidas en el Plan Gas I, podrían solicitar el cese de su participación y la incorporación a este nuevo régimen promocional.

La falta de información acerca de los proyectos aprobados, y de sus respectivas variables, impide la realización de un cálculo preciso de los resultados productivos. En la Tabla 1, se presentan datos recogidos en concepto de transferencia a los capitales privados. Entre 2013 y 2015 , las obligaciones asumidas por ambos programas totalizaron US\$ 4.886 millones.

Tabla 1. Transferencias por Planes Gas I y II (en millones de US\$)

\begin{tabular}{lllll} 
& 2013 & 2014 & 2015 & Tołal \\
\hline Devengado en Cuentas Generales de Inversión & 1.143 & 1.391 & 1.284 & \multirow{2}{*}{4.886} \\
Deuda al 31/12/2015 reconocida por Decreto N ${ }^{\circ} 704 / 16$ & - & - & 1.068 & \\
Beneficios YPF según EECC al 31/12/2015 & 786 & 955 & 1.333 & 3.074
\end{tabular}

Fuente: elaboración propia basada en datos de Secretaría de Hacienda de la Nación (2020), Decreto N 704/16 (Poder Ejecutivo Nacional, 2016) e YPF (2015).

YPF fue la principal favorecida por estos estímulos, con una participación que puede estimarse en torno al $60 \%{ }^{5}$. Ello se desprende de: a) La relación entre los beneficios declarados

5 Agradezco a Facundo López Crespo el señalamiento de un error en un cálculo previo. por la compañía en sus estados contables y las obligaciones asumidas por el Estado, según la Tabla 1 ; b) el monto recibido por la emisión de BONAR 2020 -US\$ 630 millones-, según los Estados Contables hasta el 31/12/2016 (YPF, 2016).

La afirmación es consistente con las tendencias seguidas por la producción de gas a partir 
de enero de 2013. La Figura 3 muestra que, aproximadamente desde julio, se genera un desacople entre la performance del conjunto de compañías que adhirieron al Plan Gas I y la del resto. Del primer universo, sin embargo, YPF es la única que evidencia una sostenida tendencia creciente de la producción, que tracciona los resultados generales. La producción total de las demás beneficiadas por la aprobación de proyectos para el Plan Gas I, en cambio, no escapa a la paulatina caída de la extracción que domina al resto.

Como reverso de estas medidas de estímulo, y frente al creciente efecto distorsivo de los subsidios, en 2014 el Gobierno tomó la decisión de adecuar los cuadros tarifarios de distribución de gas natural (Secretaría de Energía de la Nación, 2014) -la primera modificación integral desde 2004-. Mediante el mecanismo pass-through, se trasladó a la tarifa final un aumento promedio del $550 \%$ del precio del gas en el PIST y un $20 \%$ del costo de transporte; a eso se adicionó un incremento del margen de distribución (Serrani, 2020). Las tarifas se incrementarían gradualmente de modo diferencial, buscando propiciar una mayor reducción de subsidios entre los usuarios residenciales de consumo alto. No obstante, ese mismo año, un conjunto de medidas cautelares bloqueó la transición. Durante 2015, ante un mapa caótico de tarifas gasíferas a nivel nacional y una acumulación de deudas con las productoras, el Estado debió transferir $\$ 2.590$ millones a las distribuidoras (Serrani, 2018).

\subsection{La ley de hidrocarburos $\mathrm{N}^{\mathrm{O}}$ $27.007 / 14$}

La asociación de YPF con Chevron había evidenciado la necesidad de contar con un marco regulatorio que facilitara el desembarco de otros capitales internacionales. Autorizados por el Poder Ejecutivo, en diciembre de 2013, los equipos técnicos de YPF comenzaron a elaborar una propuesta, con el objetivo de que fuera aprobada por el Congreso de la Nación a mediados de 2014.

El proyecto presentado consolidaba la correlación entre la explotación de HNC y el cumplimiento de los principios rectores fijados por la LSH. La política de autoabastecimiento debía incentivar la producción propia "como recurso estratégico", y la intervención del Estado era determinante para definir la política de producción y de precios. El objetivo final era lograr un equilibrio entre la "ganancia razonable" para los capitales privados involucrados y la competitividad internacional de la industria doméstica.

Con todo, la propuesta implicaba una flexibilización general de las condiciones de

Figura 3. Evolución de la producción de Gas (enero-2013 a diciembre-2015)

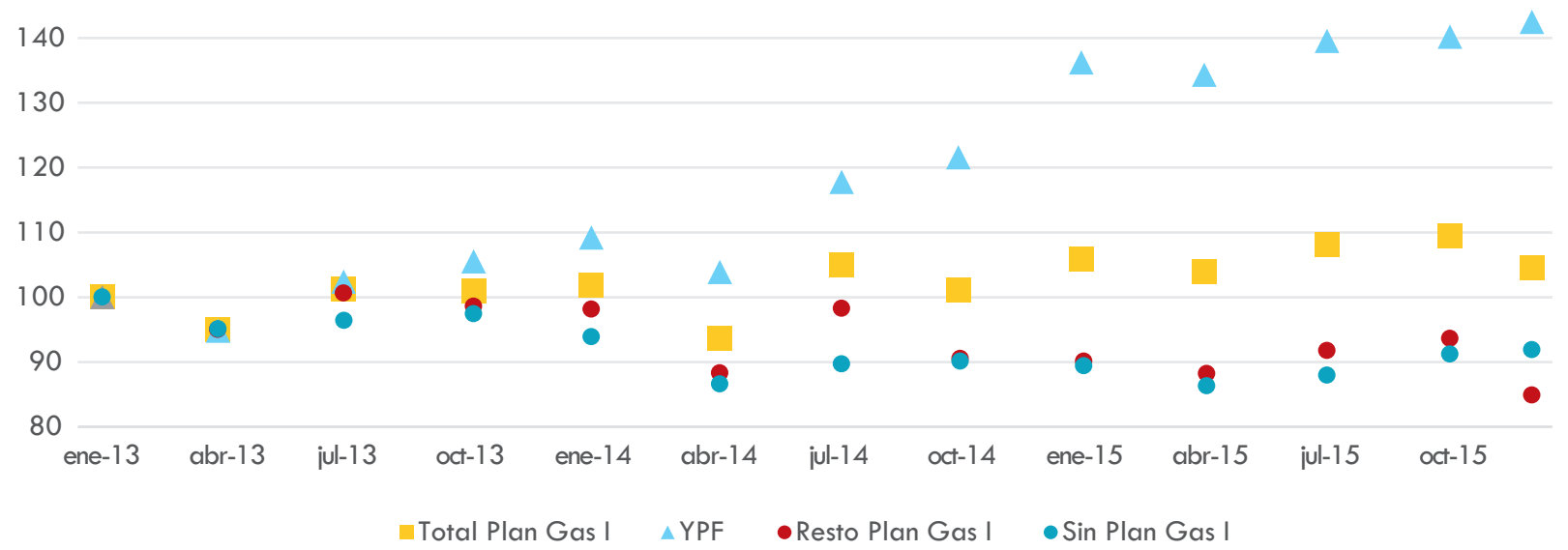

Fuente: elaboración propia basada en datos de Secretaría de Energía de la Nación (2020). 
acumulación de los capitales petroleros. En primer lugar, se introducían distintas modificaciones a la Ley de hidrocarburos $N^{\circ} 17.319 / 67$ (Congreso de la Nación Argentina, 2014b):

a. Artículos $1^{\circ}$ al $8^{\circ}$ : definían objetivos "convencionales", "no convencionales" y "en la plataforma continental y en el mar territorial", con el propósito de fijar pautas contractuales acordes al riesgo geológico y las inversiones requeridas en cada caso;

b. Artículos $11^{\circ}$ al $13^{\circ}$ : establecían la necesidad de llevar a cabo licitaciones competitivas con base en un pliego modelo consensuado entre las autoridades de aplicación de las provincias y Secretaría de Energía de la Nación;

c. Artículos $14^{\circ}$ al $16^{\circ}$ : limitaban la imposición de tributos por regalías y el otorgamiento de prórrogas de concesiones de explotación;

d. Artículo 180: impedía la reserva de nuevas áreas en favor de empresas públicas provinciales. En el caso de las que ya hubiesen sido reservadas, podrían celebrar contratos solo a condición de que la participación de dichas entidades fuera proporcional a las inversiones que realizaran.

En segundo lugar, el proyecto receptaba el régimen creado mediante el Decreto No 929/13, aunque reducía sensiblemente la inversión necesaria para acceder a sus beneficios, a un mínimo de US\$ 250 millones durante los primeros tres años del proyecto. Los estímulos previstos en dicha normativa se aplicarían al $20 \%$ de los hidrocarburos de las explotaciones convencionales y no convencionales, así como al $60 \%$ de los de las explotaciones costa afuera (artículos $19^{\circ}$ y $20^{\circ}$ ). A su vez, la importación de bienes de capital e insumos imprescindibles para la ejecución de los planes de inversión recibirían beneficios impositivos establecidos por el Decreto No 927/13 (Poder Ejecutivo Nacional, 2013b).

El proyecto reflejaba la necesidad de adecuar el entramado normativo vigente y los estímulos económicos a una realidad geológica más compleja. Un aspecto relevante era el planteo de límites a la proliferación de regímenes, re- gulaciones y tributos, resultante de la gestión provincializada de los recursos. De modo que, al articulado precedente, se le añadían una serie de compromisos entre la Nación y las provincias con respecto a la legislación ambiental y el tratamiento fiscal (artículos $23^{\circ}$ y $24^{\circ}$ ); la exclusividad del Poder Ejecutivo en la gestión de los planes de estímulo; y la unificación de procedimientos y registros de información (artículo 26ㅇ (Congreso de la Nación Argentina, $2014 b)$. En línea con la trayectoria de la intervención del Estado a partir de 2012, la propuesta de reforma constituía un paso más hacia la centralización de la política energética.

Por este motivo, la formulación del proyecto había sido objeto de duras negociaciones entre la Nación, YPF y la Organización Federal de Estados Productores de Hidrocarburos (OFEPHI). Precisamente, el recorte de diversas facultades de las provincias al momento de negociar la explotación de sus áreas hidrocarburíferas fue uno de los ejes que aglutinó a varios sectores de la oposición en contra del proyecto oficial. Junto a este, otros dos temas concitaron rechazo: los beneficios otorgados a los inversores en términos de plazos de concesión, montos requeridos para acceder a estímulos, facilidad de importación de bienes de capital e insumos ${ }^{6}$; y la escasa atención dada a las múltiples denuncias, moratorias y prohibiciones adoptadas a nivel internacional a raíz de las consecuencias socio-ambientales del fracking7 (Bertinat et al., 2014; Concerned Health Professionals of NY et al., 2019).

Durante varios momentos del debate, el Gobierno y sus aliados se valieron de la activa participación de Galuccio -promotor de las modificaciones y figura que gozaba de relativo consenso transversal (Ybarra, 2014)-. Tal como anticipaban los considerandos del proyecto, el

6 Consultar, por ejemplo, la intervención del Senador Fernando Solanas durante el debate en el recinto (Cámara de Senadores de la Nación, 2014, p. 120).

7 Ver, por ejemplo, la intervención de la senadora Magdalena Odarda (Frente Progresista-CCARI, Río Negro), quien mejor sintetizó las objeciones existentes a la utilización de esta técnica (Cámara de Senadores de la Nación, 2014, pp. 34-39). 
núcleo de la argumentación fue la necesidad de atraer inversiones para abrir el potencial de la geología nacional y lograr el autoabastecimiento. Como sinceró Miguel Pichetto, durante el cierre del debate en la Cámara de Senadores,

Analizamos Vaca Muerta como un lugar y un horizonte deseado para la Argentina, como un lugar promisorio desde el punto de vista de las expectativas; [pero] Necesitamos muchos Chevron y fuertes inversiones en el desarrollo de Vaca Muerta para extraer el gas y el petróleo, y para lograr reducir el déficit de la balanza comercial (Cámara de Senadores de la Nación, 2014, p. 138).

Apoyado en sus votos, el oficialismo logró la aprobación en la Cámara de Senadores tras solo dos jornadas de debate en comisión y en veinte días desde su ingreso por mesa de entradas. Ocurrió de igual modo en la Cámara de Diputados. El proyecto fue tratado el 21 de octubre en un plenario de las comisiones de Asuntos Constitucionales, de Energía y de Presupuesto. Ese mismo día, el oficialismo decidió emitir dictamen favorable y llevar el tratamiento definitivo al recinto la semana siguiente. El 30 de octubre, fue convertido en ley (Congreso de la Nación Argentina, 2014b) y promulgado.

\subsection{Contención de impactos frente al cambio de las condiciones internacionales}

A mediados de 2014, comenzó una fase de elevada volatilidad de la cotización internacional del crudo y sus derivados. Entre el segundo trimestre de 2014 y el último de 2015 , el precio del Brent cayó de US\$ 109 a US\$ 43 por barril. Estos movimientos estuvieron determinados por una agudización de las presiones competitivas. La demanda mundial de petróleo pasó de un crecimiento anual acumulativo de 1,8\% entre 2002-2008, a otro de 1,4\% hasta 2015, incluyendo dos caídas en el primer y último cuatrimestre de ese año. Aunque la producción tendió a acompañar este movimiento, desde el primer cuatrimestre de 2014 se observa una notable sobreoferta, que llegó a superar los 2 millones de $\mathrm{bbl} / \mathrm{d}$ en el segundo cuatrimestre de 2015 (IEA, 2020).
El desarrollo de explotaciones de HNC en Norteamérica tuvo una influencia decisiva en este proceso. Desde mediados de los 2000, la producción petrolera de Estados Unidos revirtió una tendencia declinante que llevaba más de dos décadas (EIA, 2020). La sustitución de importaciones estadounidense y su creciente relevancia como competidor profundizó fisuras en el seno de la OPEP, que expresaban la dilución de su control sobre la oferta mundial. Ante la posibilidad de que la habitual política de recortes condujera a una creciente pérdida de participación a mano de otros jugadores, durante 2015 Arabia Saudita y el resto de los integrantes del cártel continuaron expandiendo su extracción. Lo propio ocurrió con otros países relevantes, así como entre las big oil que habían concretado inversiones destinadas a ampliar la capacidad productiva antes del derrumbe de los precios (Friedman et al., 2015). En el caso de los frackers estadounidenses, la extracción pudo incrementarse gracias a una combinación de reducciones de costos, sucesivas mejoras de la productividad, pero, principalmente, sobre la base de un creciente endeudamiento (Hipple, 2020).

A partir del segundo semestre de 2014 , la situación derivó en "una suerte de guerra de trincheras en la industria petrolera, donde todos los productores tratan de ganar cuota de mercado a cualquier costo. Esto genera ganadores y perdedores en todo el mundo" (Gold, 2015, párr. 4). En este tablero, la situación argentina era ambigua. En lo inmediato, la tendencia bajista constituyó un alivio para las cuentas externas. Entre 2013 y 2015 , las cantidades importadas cayeron un 8,5\% (Secretaría de Energía de la Nación, 2020) mientras que la factura de importaciones energéticas se redujo un $45 \%$, de US\$ 12.464 a US\$ 6.841 millones (INDEC, 2020). Aunque la situación también impactó sobre el ingreso de divisas originado por las exportaciones de crudo y derivados -que experimentaron una caída del $59,5 \%$, de US\$ 5.561 a US\$ 2.251 millones-, el resultado general fue una reducción de prácticamente US\$ 2.300 millones del déficit de la balanza comercial energética, que alcanzó los US\$ 4.590 millones (INDEC, 2020). 
Pero, como espacio receptor de inversiones internacionales, la volatilidad de las cotizaciones amenazaba con colocar en un prolongado impasse el conjunto de condiciones generadas con el objetivo de explotar masivamente HNC. Entretanto, debía garantizarse su viabilidad comercial. El mecanismo privilegiado fue el mantenimiento de un "precio sostén" de la producción de crudo en el mercado interno, por encima del vigente mundialmente. Durante el segundo semestre de 2014, la brecha entre ambas cotizaciones fue reduciéndose hasta invertirse en diciembre de ese año. Desde entonces, los precios internos se mantuvieron, en promedio, un $40 \%$ más elevados que los internacionales - Ilegando a diciembre de 2015 con una brecha de prácticamente el $60 \%$-. Nuestra estimación ${ }^{8}$, plasmada en la Figura 4, arroja una transferencia aproximada de US\$3.700 millones de parte de todos los segmentos de producción y consumo en favor de los capitales petroleros.

A su vez, se modificó el sistema de derechos de exportación. La Resolución No 1.077/14 (Ministerio de Economía y Finanzas Públicas, 2014) estableció nuevos precios internacionales de referencia y alícuotas de retención. Para el petróleo y productos derivados, alcanzaría el $1 \%$ en caso de que el precio internacional del barril fuera menor a US\$ 71 y sería móvil si se ubicaba en ese nivel o lo superaba. Como muestra la Figura 5, esta última modificación tornó insignificante la percepción de derechos de exportación durante 2015.

Finalmente, a comienzos de febrero de 2015, la Resolución No 14 (CPCE, 2015) creó el "Programa de Estímulo a la Producción de Petróleo Crudo". La medida buscó incrementar la producción de crudo Medanito para el autoabastecimiento, así como el sostenimiento de la actividad y el empleo en las cuencas cuya producción se destinara mayormente a la exportación. En concreto, el programa estableció: a) una compensación económica por un monto equivalente en pesos de hasta US $\$ 3 / \mathrm{bbl}$, siempre que en cada trimestre la extracción de crudo fuera mayor o igual a la producción total de crudo correspondiente al cuarto trimestre de 2014, y que los precios de referencia de las cuencas sumados al estímulo no superaran los US\$ 84/bbl (crudo Medanito) o los US\$70/bbl (crudo Escalante); b) un estímulo a la exportación de saldos, mediante el otorgamiento de una compensación económica pagadera en pesos de hasta US $\$ 2 / \mathrm{bbl}$, a favor de las empresas que destinaran parte de su producción al mercado externo. En caso de que el

Figura 4. Transferencias por precio sostén del barril de crudo en el mercado interno, en millones de US\$ (diciembre 2014-diciembre 2015)

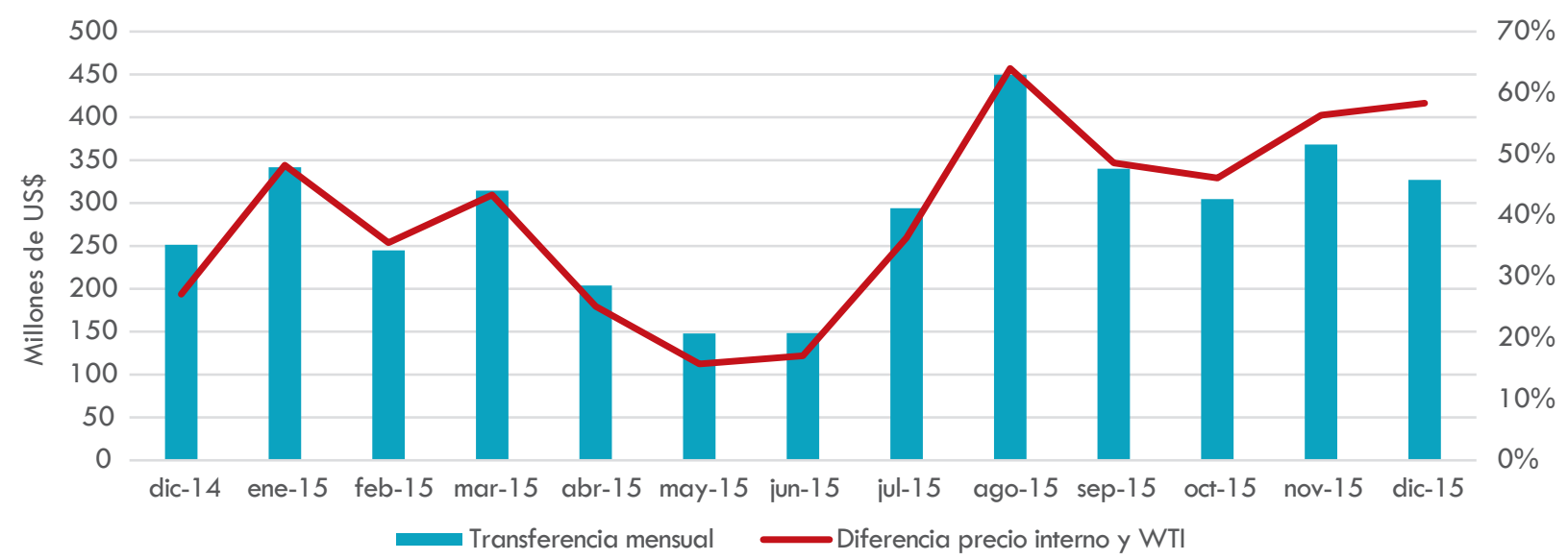

Fuente: elaboración propia basada en datos de Secretaría de Energía de la Nación (2020).

8 El cálculo consistió en el producto de: (precio promedio interno - cotización internacional) * producción destinada al mercado interno. Ver, asimismo, López-Crespo et al. (2016). 
Figura 5. Derechos de exportación percibidos por hidrocarburos y derivados, en millones de US\$ (2006-2015)

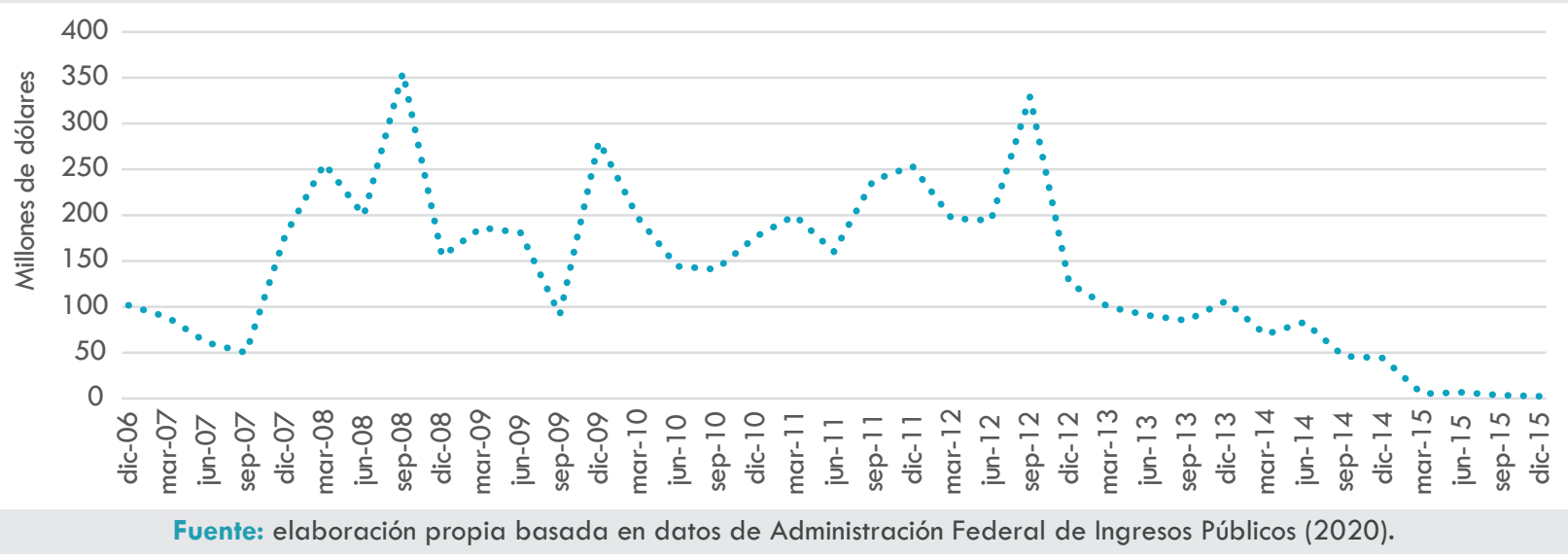

promedio de exportación trimestral se ubicara por encima del alcanzado en 2014 , el monto del estímulo ascendería hasta el equivalente a US\$ 3/bbl (CPCE, 2015). A los efectos de optimizar los resultados, las compañías que mantuvieran o incrementaran su producción trimestral y que destinaran parte de la misma a la exportación, percibirían simultáneamente ambas compensaciones económicas.
El programa estaría vigente entre el 1 de enero y el 31 de diciembre de 2015 , con la posibilidad de una prórroga por 12 meses. De acuerdo a nuestra estimación -Tabla 2-, la mayoría de las compañías se vio alcanzada por los estímulos a la producción. En total, se destinaron US\$300 millones, de los cuales US $\$ 122,5$ millones y US\$111,1 millones correspondieron a YPF y PAE, respectivamente.

Tabla 2. Transferencias con motivo del "Programa de Estímulo a la producción de petróleo crudo" (CPCE, 2015)

\begin{tabular}{|c|c|c|c|c|c|c|c|c|c|c|}
\hline \multicolumn{11}{|c|}{ Estimación de beneficios a la producción } \\
\hline \multirow{3}{*}{ Empresa } & \multirow{3}{*}{$\begin{array}{l}\text { Produc- } \\
\text { ción base } \\
\text { IVQ2014 } \\
\text { (bbl/d) }\end{array}$} & \multicolumn{4}{|c|}{ Producción total (bbl/d) } & \multicolumn{4}{|c|}{ Estímulo (millones US\$) } & \multirow[t]{3}{*}{ Total } \\
\hline & & IQ2015 & IIQ2015 & IIIQ2015 & IVQ2015 & IQ2015 & IIQ2015 & IIIQ2015 & IVQ2015 & \\
\hline & & & & & & & & & & \\
\hline PAE & 98.946 & 99.961 & 101.231 & 102.078 & 102.742 & 26,99 & 27,64 & 28,17 & 28,36 & 111,1 \\
\hline YPF S.A. & 221.036 & 218.087 & 221.101 & 220.775 & 225.495 & - & 60,36 & - & 62,24 & 122,6 \\
\hline Resto & - & - & - & - & - & 13,29 & 29,78 & 12,23 & 9,91 & 65,2 \\
\hline Total & - & - & - & - & - & 40,28 & 117,78 & 40,40 & 100,50 & 298,9 \\
\hline \multicolumn{11}{|c|}{ Estimación de beneficios a la exportación } \\
\hline \multirow{2}{*}{ Empresa } & $\begin{array}{l}\text { Exporta- } \\
\text { ción base } \\
2014\end{array}$ & \multicolumn{4}{|c|}{ Exportación total (bbl) } & \multicolumn{4}{|c|}{ Estímulo (millones US\$) } & Total \\
\hline & $\begin{array}{c}(\mathbf{b b l} / \\
\text { trimestre) }\end{array}$ & IQ2015 & IIQ2015 & IIIQ2015 & IVQ2015 & IQ2015 & IIQ2015 & IIIQ2015 & IVQ2015 & \\
\hline PAE & 3.082 .913 & 3.413 .483 & 3.125 .786 & 1.122 .298 & 3.478 .894 & 10 & 9 & 2 & 10 & 32,3 \\
\hline Tecpetrol & 484.036 & 692.521 & 262.391 & - & 788.166 & 2 & 1 & - & 2 & 4,9 \\
\hline Resto & - & - & - & - & - & 0 & 0 & 0 & 1 & 1 \\
\hline Total & - & - & - & - & - & 12 & 10 & 2 & 14 & 38,3 \\
\hline
\end{tabular}


En el caso de los beneficios a la exportación, la suma ascendió a US\$38 millones, de los cuales US\$32,2 millones fueron percibidos por PAE (ver, asimismo, López-Crespo et al., 2016).

\subsection{Los resultados del período 2012-2015}

La LSH marca un quiebre respecto del prolongado proceso de declive de la industria petrolera. Como muestran la Figura 6 y la Figura 7, las caídas de la producción de petróleo y gas -que se arrastraban desde 1999 y 2005, respectivamente- se desaceleraron entre 2013 y 2014. En 2015, la extracción de petróleo se estabilizó en 31,9 $\mathrm{MMm}^{3}$. La de gas, alentada por la vigencia de distintos instrumentos de promoción, se incrementó un 3,4\% y alcanzó $42.790 \mathrm{MMm}^{3}$.

En ambos rubros resultó crucial el creciente aporte de los HNC. Entre 2012 y 2015 , las inversiones destinadas a este tipo de recursos ascendieron de un $18 \%$ a un $32 \%$ del total (Secretaría de Energía de la Nación, 2020). Los mayores des-

Figura 6. Producción total de petróleo, en $\mathrm{m}^{3}$ (2009-2015)

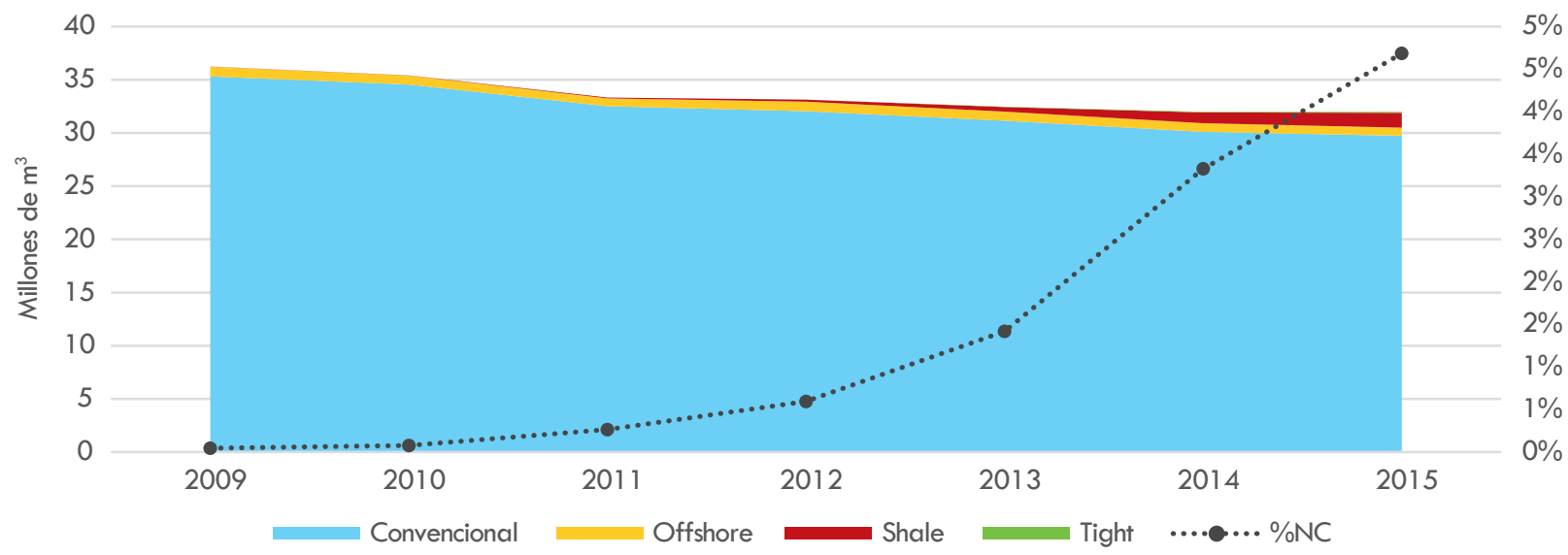

Fuente: elaboración propia basada en datos de Secretaría de Energía de la Nación (2020).

Figura 7. Producción total de gas, en $\mathrm{MMm}^{3}$ (2009-2015)

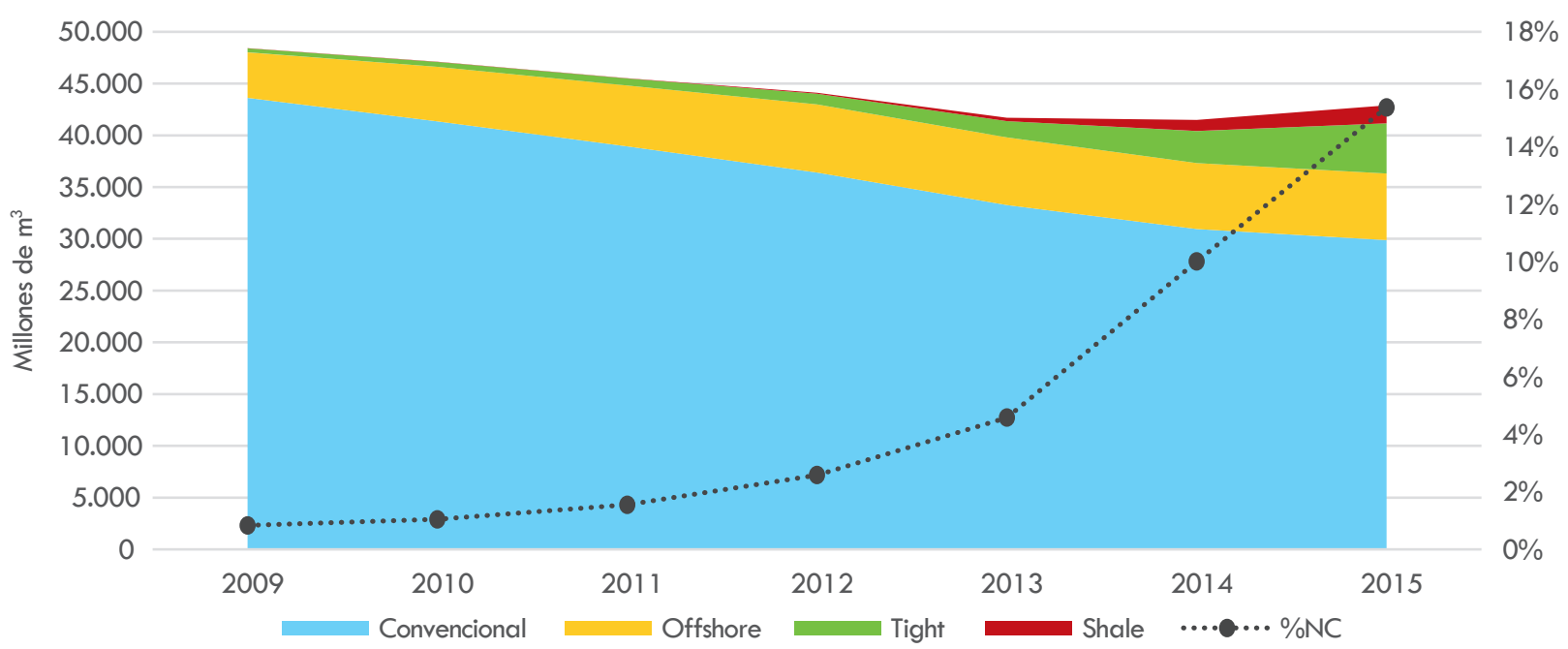

Fuente: elaboración propia basada en datos de Secretaría de Energía de la Nación (2020). 
embolsos se tradujeron en una multiplicación de los pozos realizados por año, así como en una mejora sustancial de la productividad. En el caso del petróleo, la caída de la extracción convencional y offshore fue compensada por un sostenido incremento de la producción de shale oil, que llegó a representar un $4,5 \%$ del total. En el caso del gas, la extracción de tight y shale pasó del 1,5\% al 15,3\% del total entre 2011-2015. Contrapesó, de esta manera, el declive de la producción convencional y el estancamiento del offshore.

En el caso del shale, subtipo de recurso que lideraría la expansión de la producción desde entonces, fueron decisivas las inversiones realizadas en las concesiones de explotación Loma Campana y El Orejano, tras los acuerdos alcanzados con Chevron y Dow, respectivamente. En 2015, Loma Campana aportó el $96 \%$ del total del shale oil y el $71 \%$ del shale gas extraídos; respecto del último fluido, El Orejano sumó un $26 \%$ de la producción. El ingreso de estos capitales -sobre todo de Chevron- permitió que YPF avanzara en su estrategia de delimitación e inicio de la curva de desarrollo de Vaca Muerta.

Si las políticas de posicionamiento y atracción fueron exitosas en ese plano, también debe señalarse que no produjeron un cambio de tendencia significativo en lo que respecta al comportamiento inversor del resto de los capitales. Entre 2012 y 2015 , el conjunto de los desembolsos destinados a exploración y producción creció a una tasa anual del $23 \%$, similar a la del período 2009-2012. Favorecida por una notable mejora de sus precios de realización -ver Tabla 3-, la inversión de YPF pasó de representar el 21,6\% del total en 2009, al 50\% en 2015. Ello explica que, de 2011 a 2015, YPF ampliara su peso sobre la producción total de petróleo y gas del $32,8 \%$ al $44,2 \%$ y del $23,2 \%$ al 33,3\%, respectivamente. En relación con las inversiones en HNC, la participación de YPF creció del 49,2\%, en 2012, al 68\% en 2015. Como resultado, se observa el desarrollo de una curva de aprendizaje que redujo los costos de perforación de pozos verticales y horizontales (YPF, 2017). En 2015, los rendimientos de la compañía alcanzaron a explicar el $88,5 \%$ y el $58,3 \%$ del total de la producción de petróleo y gas no convencional, respectivamente.

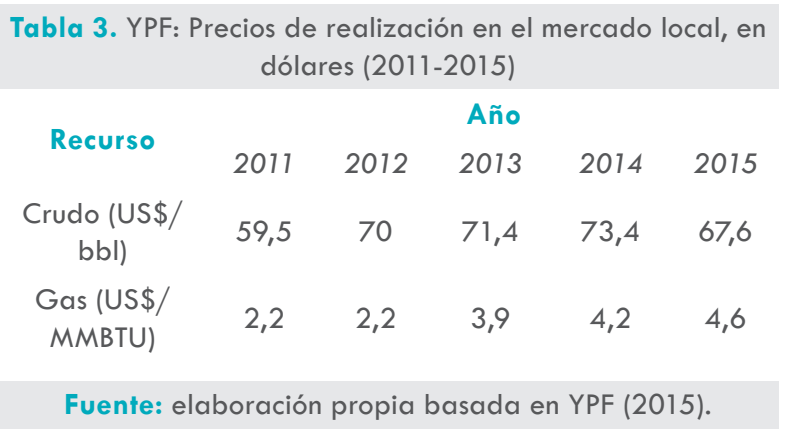

Las señales de precios encontraron ese límite pese a su onerosa carga. López-Crespo et al. (2016) estiman que, en 2015, las transferencias totales superaron los US\$ 6.500 millones y llegaron a representar un $48 \%$ de los ingresos del sector. En el caso del gas natural, el $47 \%$ de lo percibido por el productor correspondía a los distintos incentivos (Secretaría de Energía de la Nación, 2019). La Figura 8 muestra el impacto de las políticas de posicionamiento del período 2012-2015 sobre el conjunto de las erogaciones destinadas a subsidiar la producción y el consumo de energía.

Este esquema de estímulos se insertaba en una fase de estancamiento de la postconvertibilidad (Piva, 2020a) y contribuía a la progresiva pérdida de sus fuentes vitales. La creciente magnitud de los subsidios energéticos hizo un aporte decisivo a la reaparición y agravamiento de la crisis fiscal. Como muestra la Tabla 4, en 2015 el resultado primario del sector público nacional arrojó un déficit del 3,8\% del PIB.

La crisis fiscal expresaba un cuadro general de disminución de recursos materiales y de debilitamiento de las capacidades de intervención estatal. Entre 2011 y 2015 , las exportaciones cayeron un $18,6 \%$ en cantidades -especialmente las Manufacturas de Origen Industrial, que descendieron un $34,7 \%$ - y los términos del intercambio se deterioraron un $12,7 \%$, según el índice elaborado por el INDEC (2020). En 2015, la balanza comercial arrojó saldo negativo por primera vez desde 1999. Este resultado fue determinante para el agravamiento del déficit por cuenta corriente, impulsado por la salida de divisas a través de las cuentas de rentas y de servicios. En este marco, las dificultades de acceso al endeudamiento externo redoblaban la presión sobre las reservas del BCRA, que se redujeron un $45 \%$ en el período 2012-2015. 
Figura 8. Subsidios a la energía, como \% del PIB (2003-2015)

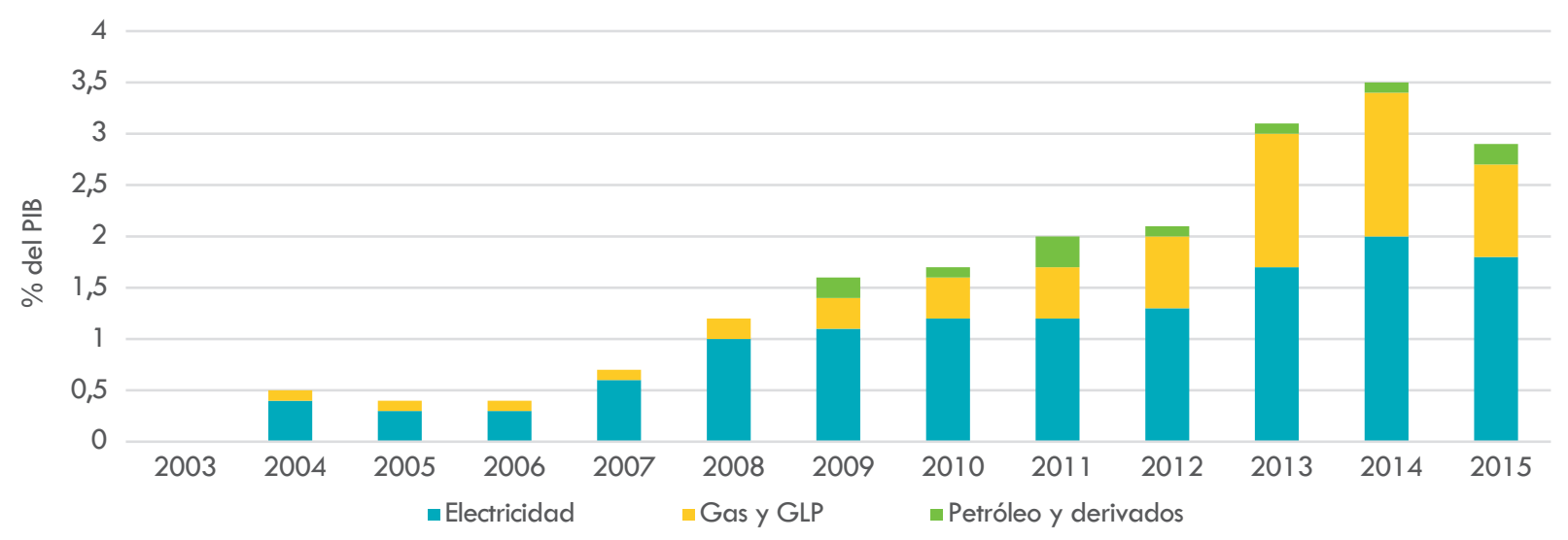

Fuente: tomado de Secretaría de Energía de la Nación (2019).

Tabla 4. Crecimiento del PIB, exportaciones según índice de cantidad, balanza de pagos, resultado fiscal primario y subsidios a la energía

Tasa anual de crecimiento PIB (2012-2015)

Exportaciones según índice de cantidad (2011-2015)

Resultado de balanza comercial (2015)

Resultado por cuenta corriente como porcentaje del PIB (2015)

Variación de las reservas internacionales BCRA (enero 2012- diciembre 2015)

Resultado primario (SPNF) como porcentaje del PIB (2015)

Subsidios a la energía como porcentaje del PIB (2015)

$$
\begin{aligned}
& 0,8 \% \\
& -18,6 \% \\
& \text { US\$ }-3.419 \text { millones } \\
& -3 \% \\
& \text { US\$ }-20.668 \text { millones } \\
& -3,8 \% \\
& 2,9 \%
\end{aligned}
$$

Fuente: elaboración propia basada en datos de INDEC (2020), Ministerio de Economía (2020) y Secretaría de Energía de la Nación (2019).

La pérdida de dinamismo de la economía se tradujo en una desaceleración del consumo total de energía, que pasó de una tasa anual de crecimiento del 2,6\%, en el período 2003-2012, a una del $1 \%$ entre 2013-2015. Este factor también explica la reducción del déficit externo del sector señalado más arriba y llama la atención acerca de los alcances de las políticas de posicionamiento. A partir de aquí, aparecerían una serie de dilemas. El eventual relanzamiento de la acumulación incrementaría rápidamente el consumo de energía. Ello podía traducirse en un crecimiento igualmente veloz de las importaciones y del déficit externo, si la producción de hidrocarburos no acompañaba la evolución de la demanda. Los resultados obtenidos entre 2013 y 2015 indicaban que tal potenciamiento dependía de la atracción de inversiones para el desarrollo de HNC. En un contexto de agudización de la competencia, sería necesario mejorar la posición de la geología local en la arena internacional. Pero los desequilibrios macroeconómicos bloqueaban la continuidad de los estímulos, tal y como venían siendo implementados. Era imposible seguir subsidiando la cadena de producción y consumo, sin exasperar la crisis fiscal. En definitiva, la intervención del Estado ya no podía diferir el dilema de quiénes debían cargar con los "verdaderos costos" de la energía.

\section{Conclusiones}

A partir de 2012, los HNC quedaron consagrados como objetivos estratégicos de la política estatal. Distintas estimaciones acerca de la magnitud y la calidad de los recursos indicaban que su explotación masiva no solo podía satisfacer las necesidades del mercado doméstico, sino también generar saldos exportables que contrarrestaran la tendencia a crisis cíclicas del sector externo. En un marco de avanzada internacionalización y 
creciente competencia entre los capitales petroleros, la concreción de esos objetivos suponía la implementación de políticas capaces de atraer y fijar inversiones productivas. De esta manera, se reforzaba objetivamente el entrelazamiento valor de uso-valor legado por las reformas neoliberales.

Esquemáticamente, las políticas de posicionamiento implementadas comprendieron cinco aspectos. En primer lugar, distintas medidas buscaron reflejar "los verdaderos costos" de la energía a partir de un cambio abrupto en la política de precios relativos ensayada hasta el momento. En segundo lugar, fueron perfeccionándose marcos regulatorios específicos para los distintos tipos de explotación, que resultaban acordes a sus tiempos, así como a sus complejidades técnicas y geológicas. En tercer lugar, se enviaron distintas señales de normalización de las relaciones entre el Estado y el mercado, resentidas tras la expropiación a Repsol. En cuarto lugar, se dotó de mayor previsibilidad a la intervención estatal, tanto a través de la centralización del control y la planificación, como mediante la armonización de prerrogativas y funciones entre la Nación y las provincias. Finalmente, YPF asumió un rol catalítico para la acumulación. Como se desprende del marco teórico de nuestro análisis, no es extraño que existan ramas o aspectos de la producción capitalista que deban ser principal o inicialmente dinamizados por el Estado. En asociación con capitales provenientes del exterior, YPF arriesgó y puso a prueba masivamente la dotación de recursos no convencionales de la geología nacional. A partir de estos desarrollos, pudo quebrar un prolongado proceso de declive de la industria petrolera. En un contexto de desaceleración económica y caída de los precios internacionales, la recuperación de la producción doméstica contribuyó a la disminución del déficit de la balanza comercial energética -uno de los principales desequilibrios de la postconvertibilidad-.

Pero este éxito también abrió distintos flancos de deslegitimación del Estado. El primero se relaciona con la aparición de un movimiento social de oposición al fracking, basado tanto en la impugnación de sus consecuencias socio-ambientales, como en concepciones antiimperialistas. Como en el caso del acuerdo con Chevron, la imposibilidad de procesar algunas de estas demandas supone una tendencia al reforzamiento del armazón coercitivo de la acción estatal.

El segundo eje de deslegitimación permaneció latente en este período, aunque su relevancia puede advertirse en la agudización de los desequilibrios de la postconvertibilidad. La política de estímulos a través del mecanismo de precios genera un dilema en torno al cubrimiento de los costos de la energía. Entre 2012 y 2015, la disyuntiva pudo postergarse -sobre todo en el caso de los precios del gas-, pero a costa de mayores erogaciones en concepto de subsidios. La magnitud del déficit fiscal de ese último año se convirtió en una presión objetiva por otro tipo de resolución, muy probablemente centrada en el incremento de los precios abonados por la demanda. Pero la factibilidad de tal respuesta no está garantizada de antemano, pues ese traslado tiene un efecto disciplinante sobre el capital a través de los costos de producción, e implica un castigo a los consumidores mediante la aplicación de nuevos cuadros tarifarios y precios de los combustibles.

De modo que las políticas de posicionamiento buscaron asegurar ventajas para la atracción y fijación de capitales internacionales que potenciaran la extracción de HNC. Pese a sus limitaciones, fueron relativamente exitosas desde el punto de vista del desarrollo de una fase inicial de testeo de la magnitud y la calidad de esos recursos. Al mismo tiempo, sin embargo, plantearon interrogantes acerca de su viabilidad política, sobre todo en un marco de agudización de la competencia internacional y de crecientes desequilibrios de la postconvertibilidad. En nuestro caso de estudio, la oposición entre Estado nacional y capital transnacionalizado de la que partimos puede ser entendida como contradicción valor de uso/valor. Es decir, como potencial imposibilidad de convalidar políticamente las condiciones de la acumulación necesarias para la apropiación de los HNC.

Esta contradicción puede ser productiva como hipótesis que oriente un próximo estudio de la política hidrocarburífera implementada por el Gobierno de la Alianza Cambiemos (20162019), en el marco de un agravamiento de los desequilibrios de la acumulación y la persistencia de la volatilidad de las cotizaciones internacionales. 


\section{Referencias}

Administración Federal de Ingresos Públicos. (2020). Estadística tributaria. https://www.afip.gob.ar/institucional/ estudios/default.asp

Altvater, E. (1977). Notas sobre algunos problemas del intervencionismo de Estado. En H. R. Sonntag y H. Valecillos (Comps.), El Estado en el capitalismo contemporáneo (pp. 88-133). Siglo XXI Editores.

Álvarez-Huwiler, L. y Bonnet, A. (2018). Ensayo y error. Un análisis marxista de las políticas públicas. Revista Mexicana de Ciencias Políticas y Sociales, LXIII(233), 169-192. http://dx.doi.org/10.22201/ fcpys.2448492xe.2018.233.59461

Astarita, R. (2004). Valor, Mercado mundial y globalización. Ediciones Cooperativas.

Astarita, R. (2010). Economía política de la dependencia y el subdesarrollo. Tipo de cambio y renta agraria en la Argentina. Universidad Nacional de Quilmes.

Barrera, M. (2013). Beneficios extraordinarios y renta petrolera en el mercado hidrocarburífero argentino. Desarrollo Económico, 53(209-210), 169-194. http://hdl.handle.net/11336/3678

Barrera, M. y Serrani, E. (2018). Energía y restricción externa en la Argentina reciente. Realidad Económica, 47(315), 9-45.

Bertinat, P., D’Elia, E., Observatorio Petrolero Sur, Ochandio, R., Svampa, M. y Viale, E. (2014). 20 mitos y realidades del fracking. El Colectivo.

Bilmes, J. (2018). Apuesta por la recuperación de YPF (2012-2015): diseño, desempeño e implicancias. Cuestiones de Sociología, (19), e063. https://doi.org/10.24215/23468904e063

Bonnet, A. (2007). Políticas neoliberales y lucha de clases. En W. Bonefeld, A. Bonnet, J. Holloway y S. Tischler (Comps.), Marxismo abierto, volumen II (pp. 141-170). Benemérita Universidad Autónoma de Puebla / Herramienta.

Bravo, V. (2015). Análisis de la ley 27007, llamada de hidrocarburos, y de la política hidrocarburífera del período 2003 a 2014 (Documento de Trabajo). Fundación Bariloche. http://fundacionbariloche.org.ar/wp-content/ uploads/2016/12/IDEE-2015-13-1.pdf

Cámara de Senadores de la Nación. (2014, 8 de octubre). Período $132^{\circ}-15^{a}$ Reunión - $7^{a}$ Sesión especial. Versión taquigráfica. https://www.senado.gob.ar/parlamentario/sesiones/08-10-2014/15/downloadTac

Casa Rosada. (2013, 16 de julio). YPF y Chevron anunciaron su acuerdo a la Jefa de Estado. http://www.casarosada. gob.ar/informacion/archivo/26585-la-jefa-de-estado-recibio-a-directivos-de-chevron-e-ypf

Concerned Health Professionals of NY, Physicians for Social Responsibility y Heinrich Böll Stiftung. (2019). Compendio de hallazgos científicos, médicos y de medios de comunicación que demuestran los riesgos y daños del fracking. https://mx.boell.org/sites/default/files/2019-11/Fracking_libro_2019.pdf

Congreso de la Nación Argentina. (2012, 3 de mayo). Ley $N^{\circ}$ 26.741. Declárase de interés público nacional el logro del autoabastecimiento de hidrocarburos. http://servicios.infoleg.gob.ar/infoleglnternet/ anexos/195000-199999/196894/norma.htm

Congreso de la Nación Argentina. (2014a, 23 de abril). Ley No 26.932. Ratifícase Convenio. http://servicios.infoleg. gob.ar/infolegInternet/anexos/225000-229999/229282/norma.htm

Congreso de la Nación Argentina. (2014b, 29 de octubre). Ley No 27.007. Modificaciones al régimen de la ley de hidrocarburos. http://servicios.infoleg.gob.ar/infoleglnternet/anexos/235000-239999/237401/norma.htm

CPCE -Comisión de Planificación y Coordinación Estratégica del Plan Nacional de Inversiones Hidrocarburíferas-. (2013a, 18 de enero). Resolución No 1. Créase el "Programa de Estímulo a la Inyección Excedente de Gas Natural". http://servicios.infoleg.gob.ar/infoleglnternet/ anexos/205000-209999/208430/norma.htm 
Sociedad y Economía N 44 (Sep - dic 2021) / e-ISSN: 2389-9050 / e10510930

Políticas de posicionamiento del sector hidrocarburífero

argentino tras la estatización parcial de YPF (2012-2015)

CPCE -Comisión de Planificación y Coordinación Estratégica del Plan Nacional de Inversiones Hidrocarburíferas-. (2013b, 1 de julio). Resolución $N^{0} 8$. Resolución $N^{0} 3 / 2013$. Modificación. http:// servicios.infoleg.gob.ar/infoleglnternet/anexos/215000-219999/217008/norma.htm

CPCE -Comisión de Planificación y Coordinación Estratégica del Plan Nacional de Inversiones Hidrocarburíferas-. (2013c, 8 de noviembre). Resolución No 8. Créase el "Programa de Estímulo a la Inyección de Gas Natural para Empresas con Inyección Reducida". http://servicios.infoleg.gob.ar/ infolegInternet/anexos/220000-224999/222998/norma.htm

CPCE -Comisión de Planificación y Coordinación Estratégica del Plan Nacional de Inversiones Hidrocarburíferas-. (2015, 3 de febrero). Resolución $N^{\circ}$ 14. "Programa de Estímulo a la Producción de Petróleo Crudo". Creación. http://servicios.infoleg.gob.ar/infoleglnternet/ anexos/240000-244999/241607/norma.htm

Cruz, C. (2005). El gran desafío de ampliar las fronteras de la exploración. Petrotecnia, XLVI(6), 8-26.

EIA -Energy Information Administration-. (2011). World Shale Gas Resources: An Initial Assessment of 14 Regions Outside the United States. https://www.eia.gov/analysis/studies/worldshalegas/archive/2011/ pdf/fullreport.pdf

EIA -Energy Information Administration-. (2013). Technically Recoverable Shale Oil and Shale Gas Resources: An Assessment of 137 Shale Formations in 41 Countries Outside the United States. https://www.eia.gov/ analysis/studies/worldshalegas/pdf/overview.pdf

EIA -Energy Information Administration-. (2020). International Energy Statistics. https://www.eia.gov/ international/data/world

Friedman, N., Ailworth, E. y Olson, B. (2015, 8 de diciembre). Los precios del crudo siguen en caída, pero nadie recorta su producción. La Nación. http://www.lanacion.com.ar/1852253-los-precios-del-crudosiguen-en-caida-pero-nadie-recorta-su-produccion

Gaggero, A., Schorr, M. y Wainer, A. (2014). Restricción eterna. El poder económico durante el kirchnerismo. Futuro Anterior.

García-Zanotti, G. (2017). El contrato entre YPF y Chevron: una forma desdibujada en la relación entre el Estado y el mercado. Cuadernos de Economía Crítica, 3(6), 127-151. http://hdl.handle.net/11336/74737

Giuliani, A. (2017). La explotación de hidrocarburos en Argentina, en el marco de la governance. El caso de Vaca Muerta. Revista Administración Pública y Sociedad, (3), 49-61.

Giustiniani, R. (2017). El contrato secreto YPF-Chevron. EUDEBA.

Gold, R. (2015, 24 de agosto). A pesar del exceso de crudo, nadie da su brazo a torcer. La Nación. http:// www.lanacion.com.ar/1 821654 -a-pesar-del-exceso-de-crudo-nadie-da-su-brazo-a-torcer

Gutiérrez, F. y Millaman, S. (2016). Campo Maripe, el resurgir mapuche en medio del avance petrolero. En VVAA, Resistencias mapuche al extractivismo (pp. 71-80). Colectivo Editorial Mapuexpress; Fundación Rosa Luxemburgo.

Hadad, M. G., Palmisano, T. y Wahren, J. (2020). Socio-territorial Disputes and Violence on Fracking Land in Vaca Muerta, Argentina. Latin American Perspectives, 48(236), 63-83. https://doi. org/10.1177/0094582X20975009

Harvey, D. (2007). Espacios del capital. Hacia una geografía crítica. AKAL.

Harvey, D. (2008). La condición de la posmodernidad. Amorrortu Editores.

Hipple, K. (2020). Bankruptcies in Fracking Sector Mount in 2019. Institute for Energy Economics and Financial Analysis. https://ieefa.org/wp-content/uploads/2020/01/Bankruptcies-in-Fracking-SectorMount-in-2019_January-2020.pdf 
Hirsch, J. (1978). The State Apparatus and Social Reproduction: Elements of a Theory of the Bourgeois State. En J. Holloway y S. Picciotto (Eds.), State and Capital (pp. 57-107). Edward Arnold Publishers.

Hirsch, J. (1999). Globalización del capital y la transformación de los sistemas de Estado: del "Estado de seguridad" al "Estado nacional competitivo". Cuadernos del Sur, 15(28), 71-82. https:// cuadernosdelsurorg.files.wordpress.com/2017/07/06_hirsch_globalizacioncapital.pdf

Holloway, J. (1993). La reforma del Estado: capital global y Estado nacional. Perfiles Latinoamericanos, (1), 7-32. https://perfilesla.flacso.edu.mx/index.php/perfilesla/article/view/492/445

Holloway, J. (1994). Marxismo, estado y capital. Tierra del Fuego.

Holloway, J. (2003). Keynesianismo: Una peligrosa ilusión: un aporte al debate de la teoría del cambio social. Herramienta.

IEA -International Energy Agency-. (2020). Data and statistics. Oil. https://www.iea.org/fuels-andtechnologies/oil

INDEC -Instituto Nacional de Estadística y Censos-. (2020). Estadísticas de Economía. Comercio exterior. https://www.indec.gob.ar/indec/web/Nivel3-Tema-3-2

Jessop, B. (2008). El futuro del Estado capitalista. Catarata.

La Nación. (2013, 18 de julio). Kicillof consideró que el acuerdo Chevron traerá "un carnaval y boom de actividad". https://www.lanacion.com.ar/economia/kicillof-considero-que-el-acuerdo-chevron-traera-unun-carnaval-y-boom-de-actividad-nid1602310/

López-Crespo, F., García-Zanotti, G. y Kofman, M. (2016). Informe económico. Transferencias al sector hidrocarburífero en Argentina. Taller Ecologista; Observatorio Petrolero Sur.

Marx, K. (2009). Elementos fundamentales para la crítica de la Economía Política (Grundrisse) 1857-1858 (Tomo I). Siglo XXI Editores.

Ministerio de Economía. (2020). Portal de datos económicos. Base de Datos Económicos Agregados (Series de Tiempo). https://apis.datos.gob.ar/series/api/dump/sspm/series-tiempo.xlsx

Ministerio de Economía y Finanzas Públicas. (2013, 3 de enero). Resolución $N^{0} 1$. Sustitúyense en el Anexo I de la Resolución No 394/2007 las posiciones arancelarias de la nomenclatura común del MERCOSUR. http://servicios.infoleg.gob.ar/infolegInternet/anexos/205000-209999/206979/norma.htm

Ministerio de Economía y Finanzas Públicas. (2014, 29 de diciembre). Resolución No 1.077. Resolución $\quad N^{\circ}$ 394/2007. Derogación. http://servicios.infoleg.gob.ar/infoleglnternet/ anexos/240000-244999/240309/norma.htm

Ministerio de Planificación Federal, Inversión Pública y Servicios, y Ministerio de Economía y Finanzas Públicas. (2012). Informe Mosconi. http://cdi.mecon.gov.ar/bases/docelec/fc1307.pdf

Ministerio Público Fiscal. (2013, 22 de mayo). Aguinda Salazar María c/Chevron Corporation s/medidas precautorias. https://www.mpf.gob.ar/dictamenes/2013/AGilsCarbo/mayo/Aguinda_Salazar_A_253_L_ XLIX.pdf

Negri, A. (2003). La forma-Estado. AKAL.

O'Connor, J. (1974). Estado y capitalismo en la sociedad norteamericana. Ediciones Periferia.

Olivera, F. (2012, 10 de julio). La crisis energética / Puja entre dos áreas. Primeros desencuentros en la nueva YPF. La Nación. https://www.lanacion.com.ar/economia/primeros-desencuentros-en-la-nueva-ypfnid1489132/

Oszlak, O. y O’Donnell, G. (1995). Estado y políticas estatales en América Latina: hacia una agenda de investigación. Redes, 2(4), 99-128. 
Sociedad y Economía N 44 (Sep - dic 2021) / e-ISSN: 2389-9050 / e10510930

Políticas de posicionamiento del sector hidrocarburífero

argentino tras la estatización parcial de YPF (2012-2015)

Pérez-Esquivel, A. (2013, 25 de julio). ¿Desarrollo o Semicolonia? http://www.adolfoperezesquivel. org/?p=3278

Pérez-Roig, D. (2020a). La recuperación del control de YPF: lógica política y constricciones económicas de la intervención estatal en la postconvertibilidad. Trabajo y Sociedad, XXI(35), 517-543. https://www.unse. edu.ar/trabajoysociedad/35\%20AA\%20Perez\%20Roig\%20Diego\%20YPF.pdf

Pérez-Roig, D. (2020b). Reestructuración del sector hidrocarburífero argentino y «estrategia de acumulación» de capital en la convertibilidad. Papers, 105(3), 449-481. https://doi.org/10.5565/rev/papers.2655

Pérez-Roig, D. (2021). Política hidrocarburífera del Estado y modo de acumulación de capital durante la postconvertibilidad argentina (2002-2011). Economia e Sociedade, 30(2), 10 . https://doi. org/10.1590/1982-3533.2021v30n2art10

Pérez-Roig, D. y Riffo, L. (2021). Políticas de promoción y límites a la obtención de hidrocarburos de reservorios no convencionales en la Provincia del Neuquén. Estudios Sociales del Estado, en prensa.

Piva, A. (2018). Política económica y modo de acumulación en la Argentina de la posconvertibilidad. Perfiles Latinoamericanos, 26(52), 1-26. https://doi.org/10.18504/pl2652-006-2018

Piva, A. (2020a). Cambios en la restricción externa y la dinámica recesiva desde 2019. Espacio Abierto. Cuaderno Venezolano de Sociología, 29(1), 141-167. https://produccioncientificaluz.org/index.php/ espacio/article/view/31411

Piva, A. (2020b). Una lectura política de la internacionalización del capital. Algunas hipótesis sobre la actual fase de la internacionalización del capital y el Estado nacional de competencia. En V. Ciolli, R. GarcíaBernado y F. Naspleda (Comps.), La dimensión inevitable. Estudios sobre la internacionalización del Estado y del capital desde Argentina (pp. 13-41). Universidad Nacional de Quilmes.

Poder Ejecutivo Nacional. (2012). Decreto No 1.277. Apruébase la reglamentación de la Ley No 26.741. http://servicios.infoleg.gob.ar/infolegInternet/anexos/200000-204999/200130/norma.htm

Poder Ejecutivo Nacional. (2013a, 11 de julio). Decreto No 929. Créase el régimen de promoción de inversión para la explotación de hidrocarburos. http://servicios.infoleg.gob.ar/infoleglnternet/ anexos/215000-219999/217314/norma.htm

Poder Ejecutivo Nacional. (2013b, 8 de julio). Decreto No 927. Bienes de Capital comprendidos en las posiciones arancelarias. http://servicios.infoleg.gob.ar/infolegInternet/anexos/215000-219999/217419/norma. htm

Poder Ejecutivo Nacional. (2016, 20 de mayo). Decreto No 704. Bonos de la Nación Argentina en Dólares Estadounidenses 8\% 2020 (BONAR 2020 USD). Dispónese ampliación. http://servicios.infoleg.gob.ar/ infolegInternet/anexos/260000-264999/261638/norma.htm

Poulantzas, N. (2007). Poder político y clases sociales en el Estado capitalista. Siglo XXI Editores.

Repsol YPF. (2012a, 8 de febrero). Hecho Relevante No 157656. https://www.repsol.com/imagenes/global/ es/20120208vaca-muerta-co_tcm13-14025.pdf

Repsol YPF. (2012b, 3 de diciembre). Hecho Relevante $N^{\circ}$ 178220. https://www.repsol.com/imagenes/ global/es/Solicitud_CIADI_tcm13-13973.pdf

Riffo, L. (2017). Hidrocarburos no convencionales y conflictos socioambientales. Análisis crítico de la escena enunciativa en el diario Río Negro sobre el Acuerdo Chevron-YPF S. A. (En)clave Comahue. Revista Patagónica de Estudios sociales, 24(23), 61-84. http://revele.uncoma.edu.ar/htdoc/revele/index.php/ revistadelafacultad/article/view/1617

Rubin, I. I. (1974). Ensayos sobre la teoría marxista del valor. Ediciones Pasado y Presente. 
Secretaría de Energía de la Nación. (2012, 21 de junio). Resolución Nº 438. Otórgase una compensación a las empresas que realicen exportaciones de petróleo crudo. http://servicios.infoleg.gob.ar/infoleglnternet/ anexos/195000-199999/198999/norma.htm

Secretaría de Energía de la Nación. (2014, 31 de marzo). Resolución No 226. Esquema de racionalización de uso del Gas Natural. http://servicios.infoleg.gob.ar/infolegInternet/anexos/225000-229999/228576/ norma.htm

Secretaría de Energía de la Nación. (2019). Argentina: Evolución de subsidios, oferta y demanda de energía 2015-2019. http://www.energia.gob.ar/contenidos/archivos/Reorganizacion/sintesis_balance/2019-11-20_ SE_Subsidios_oferta_y_demanda_de_energia_Argentina_2015-2019_dist.pdf

Secretaría de Energía de la Nación. (2020). Información estadística sobre Hidrocarburos. https://www. argentina.gob.ar/economia/energia/hidrocarburos

Secretaría de Hacienda de la Nación. (2020). Cuenta de Inversión. https://www.argentina.gob.ar/economia/ sechacienda/cgn/cuentainversion

Serrani, E. (2018). Transformaciones tarifarias y efectos en la región patagónica. Camuzzi Gas del Sur y la distribución de gas natural, 1999-2017. Revista Identidades, 8(14), 45-70. https://iidentidadess.files. wordpress.com/2018/08/03-identidades-14-8-2018.pdf

Serrani, E. (2020). Modelos de regulación de servicios públicos de gas natural en Argentina, 1967-2017. América Latina en la Historia Económica, 27(2), https://doi.org/10.18232/alhe.1062

Unión de Afectados y Afectadas por las Operaciones Petroleras de Texaco. (2018). El juicio. http:// texacotoxico.net/el-juicio/

Von-Braunmühl, C. (2017). El análisis del estado nacional burgués en el contexto del mercado mundial. Un intento por desarrollar una aproximación metodológica y teórica. En A. Bonnet y A. Piva (Comps.), Estado y capital. El debate alemán de la derivación del estado (pp. 697-724). Herramienta.

Ybarra, G. (2014, 2 de octubre). Avanza en el Senado la nueva ley petrolera. La Nación. http://www.lanacion. com.ar/1732082-avanza-en-el-senado-la-nueva-ley-petrolera

Yergin, D. (2008). The Prize. The epic quest for oil, money \& power. Free Press.

YPF. (2012a, 24 de abril). Reuniones con empresas del sector. Sala de prensa. https://www.ypf.com/YPFHoy/ YPFSalaPrensa/Paginas/Noticias/Reuni\%C3\%B3n-con-Chevron-.aspx

YPF. (2012b, 24 de abril). Reunión con Exxon Mobil. Sala de prensa. https://www.ypf.com/YPFHoy/ YPFSalaPrensa/Paginas/Noticias/Reuni\%C3\%B3n-con-Exxon-Mobil.aspx

YPF. (2013, 29 de agosto). Acuerdo YPF-Chevron. Para el desarrollo de Vaca Muerta. https://www.ypf.com/ inversoresaccionistas/Lists/Presentaciones/29-08-2013-Presentacion-YPF.pdf

YPF. (2015). Estados contables consolidados al 31/12/2015. https://www.ypf.com/inversoresaccionistas/ Lists/InformacionFinanciera/EECC-\%20Consolidados-al-31-12-2015.pdf

YPF. (2016). Estados contables consolidados al 31/12/2016. https://www.ypf.com/inversoresaccionistas/ Lists/InformacionFinanciera/EECC-YPF-S.A.-Consolidados-31-12-2016.pdf

YPF. (2017). Problemática de la competitividad de la industria de O\&G local (documento inédito). Presentación preparada por las gerencias de Estrategia y de Compras y Contratos. 